\title{
EXPERIENTIA DOCET: THE EFFECTS OF SERVICE-LEARNING ON THE ACADEMIC SUCCESS OF FIRST-GENERATION STUDENTS
}

\author{
AS A dissertation submitted to the faculty of \\ 35 San Francisco State University \\ 2018 In partial fulfillment of \\ EDD \\ .467 \\ The Requirements for \\ The Degree
}

Doctor of Education

in

Educational Leadership

by

Jose R. Lopez

San Francisco, California

May 2018 


\section{Copyright by}

Jose R. Lopez 2018 


\section{CERTIFICATION OF APPROVAL}

I certify that I have read Experientia Docet: The Effects of ServiceLearning on the Academic Success of First-Generation Students by Jose R. Lopez, and that in my opinion this work meets the criteria for approving a dissertation submitted in partial fulfillment of the requirements for the degree: Doctor of Education in Educational Leadership at San Francisco State University.

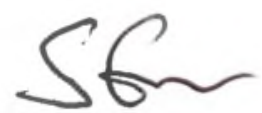

Sheldon Gen, Ph.D.

Associate Professor, Public Administration San Francisco State University

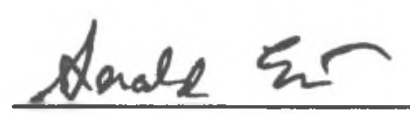

Gerald Eisman, Ph.D.

Professor Emeritus

San Francisco State University

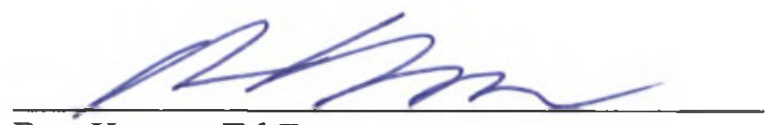

Ray Kaupp, Ed.D.

Adjunct Faculty, Educational Leadership

San Francisco State University 
EXPERIENTIA DOCET: THE EFFECTS OF SERVICE-LEARNING ON THE

ACADEMIC SUCCESS OF FIRST-GENERATION STUDENTS

\author{
Jose R. Lopez \\ San Francisco State University
}

2018

This case study uses a mix methods approach to investigate several markers of academic success for first-generation college students enrolled in service-learning courses at San Francisco State University (SFSU). Academic success is measured through GPA, retention, and graduation rates. Previous research indicates that servicelearning is an active learning practice that facilitates deep learning by promoting student engagement related to academic success. This case study uses not only in-depth interview data from 20 SFSU undergraduate but also uses secondary data from Academic Institutional Data and the National Survey of Student Engagement with 4,160 student participants. Overall, findings suggest that personal and professional development within service-learning courses provide the experience and career readiness necessary for students to engage with their education in a meaningful way. Furthermore, that collaborative learning, student-teacher interaction, and reflective and integrated learning inherent in service-learning participation contribute to the students' academic success and persistence.

I certify that the Abstract is a correct representation of the content of this dissertation.

Sheldon Gen, Ph.D.

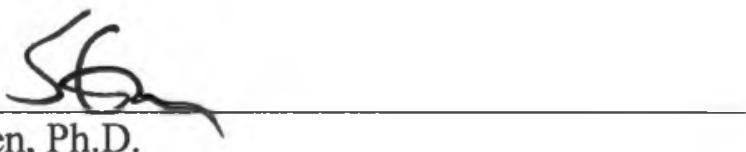

Chair, Dissertation Committee

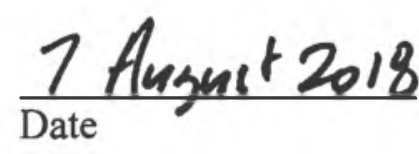




\section{ACKNOWLEDGMENTS}

This dissertation is a testament to my family and friends, who have always supported me throughout the years as I pursued my doctorate education. It has been a long and winding road, which was eight years in the making. As a first-generation college student pursuing a doctorate in education it has been one of reflection and self-discovery. It indeed took a village, and I am forever grateful to the people that have mentored me and believed in me before I believed in myself. In particular, my love and gratitude goes out to Agustin Palacios, Miguel Rodriquez, Dr. Maria Alaniz, Rudy Tovar, and the children Saul, Quetzalli, Alexis, and Xochitl who have shown me a lot a love throughout the years and have brought me into their hearts as family. Moreover, I would like to give a special thanks to Choriza, who has been a constant support throughout the doctoral program. Finally, I would like to thank my MECHA crew, who have always been an inspiration and beautiful role models in various fields, and continue to be leaders in the community 
TABLE OF CONTENTS

LIST OF TABLES

viii

LIST OF FIGURES

ix

LIST OF APPENDICES $\quad \mathrm{x}$

Chapter One: Purpose of the Study 1

Introduction $\quad 1$

Problem Statement 3

First-Generation Students 3

$\begin{array}{lr}\text { Service-Learning in Academic Affairs } & 8\end{array}$

Research Questions $\quad 9$

Conceptual Framework $\quad 10$

Definitions of Key Terms $\quad 11$

Significance of the Study 13

$\begin{array}{ll}\text { Chapter Two: Literature Review } & 15\end{array}$

Introduction $\quad 15$

$\begin{array}{lr}\text { Conceptual Framework } & 17\end{array}$

$\begin{array}{ll}\text { Education and Experience } & 17\end{array}$

The Experiential Learning Model 20

$\begin{array}{ll}\text { Theory on Retention } & 23\end{array}$

First-Generation College Students $\quad 25$

Encouragements and Encouragement $\quad 25$

Enrollment Characteristics $\quad 26$

Intervention Efforts $\quad 27$

Service-Learning in Higher Education $\quad 28$

Academic Outcomes $\quad 29$

Academic Development $\quad 29$

Grades and Test Scores $\quad 30$

Retention and Persistence $\quad 33$

$\begin{array}{ll}\text { Personal Outcomes } & 35\end{array}$

Prosocial Academic Behaviors $\quad 35$

Conclusion $\quad 38$

Chapter Three: Methodology $\quad 41$

Introduction $\quad 41$

$\begin{array}{ll}\text { Setting } & 42\end{array}$

Experentia Docet $\quad 44$

The Quantitative Data $\quad 45$

Plan of Analysis $\quad 51$

The Qualitative Data $\quad 52$

Plan of Analysis $\quad 55$ 
Ethical Consideration and Protection of Subjects $\quad 60$

$\begin{array}{ll}\text { Internal Validity } & 60\end{array}$

External Validity $\quad 62$

Chapter Four: Report of Findings $\quad 64$

$\begin{array}{ll}\text { Overview } & 64\end{array}$

Quantitative Analysis $\quad 65$

Research Question \#1 $\quad 65$

$\begin{array}{ll}\text { Freshmen Cumulative GPA } & 67\end{array}$

Freshmen Retention $\quad 68$

$\begin{array}{ll}\text { Senior Cumulative GPA } & 68\end{array}$

Senior Graduation \& Years to Degree $\quad 64$

$\begin{array}{ll}\text { Summary of Quantitative Analysis } & 72\end{array}$

$\begin{array}{ll}\text { Qualitative Analysis } & 73\end{array}$

Research Question \#2 73

Quantitative Results $\quad 74$

Qualitative Themes $\quad 85$

$\begin{array}{lr}\text { Collaborative Learning } & 85\end{array}$

$\begin{array}{ll}\text { Student-Teacher Interactions } & 91\end{array}$

$\begin{array}{lr}\text { Reflective and Integrated Learning } & 98\end{array}$

Summary of Qualitative Analysis $\quad 103$

$\begin{array}{ll}\text { Overall Discussion } & 104\end{array}$

Chapter Five: Discussion and Implications 106

$\begin{array}{ll}\text { Overview } & 106\end{array}$

$\begin{array}{ll}\text { Interpretation of Findings } & 107\end{array}$

Quantitative Analysis $\quad 107$

Qualitative Analysis $\quad 113$

Summary of Findings $\quad 121$

Limitations of Research $\quad 123$

$\begin{array}{lr}\text { Implications for Practice } & 127\end{array}$

Implications for Future Research $\quad 138$

$\begin{array}{lr}\text { Final Thoughts } & 139\end{array}$

References $\quad 143$

$\begin{array}{ll}\text { Appendices } & 148\end{array}$ 
Table

\section{LIST OF TABLES}

1. Percentage of Undergraduates who Earned a Degree by Parents' Educational Attainment

2. Percentage of Undergraduates in College Remedial Courses by Parents' Ed. Attainment

3. Percentage of Undergraduates by Race/Ethnicity

4. Frequency, Percentages, \& Means - Freshmen \& Seniors by Comparison Groups 49

5. Student Participants Characteristics by Comparison Groups

6. NSSE Themes and Engagement Indicators

7. ANOVA - Cumulative GPA by Freshmen

8. Chi-Square Retention Status with Comparison Groups

9. ANOVA - Cumulative GPA by Seniors

10. Chi-Square Graduation Status with Comparison Groups

11. ANOVA - Years to Degree by Seniors

12. Interview Responses by First-Generation Student taking Service-Learning 
Figure

1. Experiential Learning Model
LIST OF FIGURES

Page

21 


\section{IST OF APPENDICES}

Appendix

Page

1. Qualitative Interview for Service-Learning Students

148

2. Qualitative Interview for Service-Learning Students

149

3. Data Plan of Analysis

150

4. Recruitment Flyer 
Chapter One: Purpose of the Study

"Tell me and I forget, teach me and I may remember, involve me and I learn." Ancient Chinese Proverb

\section{Introduction}

This dissertation examines how service-learning has the potential to address issues of retention and academic success for first-generation college students in higher education. The low retention and graduation rates of first-generation college students compared to non-first-generation college students pose a substantial challenge for the nation's colleges and universities. According to the National Center for Education Statistics (NCES), 34\% of undergraduates were the first in their families to go to college in 2011 , and $28 \%$ of first-generation students report having a parent with some college experience, but with no bachelor's degree ("US Department of Education," 2014). In particular, only $59 \%$ of high school graduates without college-educated parents enroll in college, compared to $93 \%$ of high school graduates with collegeeducated parents (Choy, 2001). Furthermore, first-generation college students delay college entry, often need remedial coursework (Chen, 2005), and are twice as likely to drop out before their second year compared to non-first-generation college students (Engle, 2007). Therefore, this dissertation seeks to understand service-learning at San Francisco State University (SFSU) and how it affects first-generation college students' academic success and persistence. 
To address these educational disparities surrounding degree attainment mentioned above, four-year universities have begun to explore alternative instructional co-curricular practices, including service-learning. Service-learning is a teaching and learning strategy that intentionally combines experiential learning with college instruction (Jacoby, 2014). Additionally, service-learning explicitly integrates students' social and academic college experiences to increase student success and persistence (Eyler \& Giles, 1999; Gallini \& Moely, 2003; Yeh, 2010). Although prior research has established that service-learning features academic and social integration as its primary objective (Eyler \& Giles, 1999), the impact of participation in service-learning on students' grades and graduation rates is not extensively researched, especially for nontraditional students. Additionally, the research that does exist has, at times, contradictory findings regarding the various ways that service-learning pedagogy has been operationalized and evaluated at a 4-year university. The case study approach in this dissertation contributes to the understanding of service-learning at SFSU and how it can be used to enhance students' academic needs, with a particular interest in firstgeneration college students. In particular, this study identifies several effective practices utilized in service-learning and looks at the effects of service-learning on GPA, retention, and graduation, among other academic themes, of first-generation college students. 


\section{Problem Statement}

First-Generation Students. Lower rates of enrollment, retention, and degree completion for first-generation college students compared to their counterparts are the central problems this dissertation analysis addresses. First-generation students' college careers typically follow these paths; 1) they tend to go directly to a 2-year school, as opposed to a 4-year university, and 2) they attend college part-time which makes them less likely to complete their degree in six years compared to their non-first-generation counterparts ("US Department of Education," 2014). In addition to these major factors, first-generation students are less prepared for college, tend to be non-traditional and often marginalized students, come from lower socio-economic backgrounds, and are predominantly students of color, which adds additional dimensions to the equity issues being addressed for first-generation college students academic success (Choy, 2001).

Overall, there is a disproportionate number of first-generation college students who enroll in 2-year institutions rather than 4-year institutions ("US Department," 2014). Enrolling in a 2-year school can negatively affect first-generation students' chances of attaining a bachelor's degree (Cahalan et al., 2016). According to the Pell Institute (2016), first-generation college students who attend a 4-year college directly out of high school are more likely to receive a bachelor's degree than students who attend a two-year college. Students who attend community colleges are more likely to report low levels of academic support (Edman \& Brazil, 2009); therefore, the overrepresentation of first-generation students in community college, who need the 
most support, are caught in an educational system that has the least support structures, adversely affecting their academic success. It is for that reason that many students never transition to the next level and only about $25 \%$ of first-generation college students eventually attend four-year institutions (Cahalan et al., 2016)

Table 1 illustrates the percentage of undergraduates that earned a degree or certificate by parents' educational attainment. In particular, non-first-generation students who have a parent with a bachelor's degree or higher have a $59 \%$ chance to attain a bachelor's degree as well. This percentage is in stark contrast when compared to the percentage of students whose parents did not attain a bachelor's degree and only received "some postsecondary education" (42.6\%) or a "high school diploma or less" $(37 \%)$, respectively.

Table 1. Percentage of Undergraduates who Earned a Degree by Parents' Educational Attainment

\begin{tabular}{lllll}
\hline & \multicolumn{4}{c}{ Degree or Program } \\
\cline { 2 - 5 } & Certificate & Associate's & Bachelor's & $\begin{array}{l}\text { No } \\
\text { Parents' Ed. Attainment }\end{array}$ \\
\hline High School Diploma or less & 10.8 & 49.7 & 37.0 & 2.6 \\
Some Postsecondary Ed. & 7.5 & 46.3 & 42.6 & 3.6 \\
Bachelor's or Higher & 5.3 & 31.7 & 59.1 & 3.9 \\
\hline
\end{tabular}

Source: National Center for Education Statistics, 2014, p. 38.

Additional barriers that first-generation students face is their lack of full-time enrollment, which impacts degree completion. Prior research highlights essential indicators of academic success such as retention and time to degree completion, 
especially when comparing the highest degree attained by parents ("US Department," 2014). Full-time enrollment is a significant predictor for degree completion because the more time it takes students to complete their degree, the more expensive it can be, and the more other factors can intrude upon their college plans. Nonetheless, only $52 \%$ of first-generation students attend college full-time ("US Department of Education," 2014). The effects of full-time enrollment, or lack thereof, is demonstrated by the fact that only $11 \%$ of first-generation college students who enroll part-time will have a college degree within a six-year timeframe ("US Department of Education," 2014).

In addition to the three primary barriers discussed above, NCES (2014) identifies several essential characteristics first-generation college students share, including being more likely to be older than their peers, working full-time, and being responsible for dependents. In particular, retention and graduation are affected by working full-time when the student is not able to prioritize school work over their employment, especially when other people in their families are dependent on the income or they must work to pay for school. Students who share these characteristics are more likely to be non-traditional college students, and share a different set of factors that contribute to challenges related to retention, degree completion, and finishing their bachelor's degree within six years' time. Therefore, working full-time and being responsible for dependents often directly competes with the time and energy dedicated to their college careers, which can prevent them from investing full-time in completing their education within a specified timeframe. 
Furthermore, first-generation college students demonstrate low rates of college preparedness in the essential academic areas such as English and Math. Table 2 illustrates the percentage of undergraduates that took remedial college courses during 2011-2012. When combining the two sections of parents without a bachelor's degree in Table 2, a higher proportion of first-generation students with parents with less than a bachelor's degree enroll in college remedial courses in English (16.9\%), Writing (12.2\%), and Math (12.4\%). These numbers are compared to those non-first-generation students (English 6.4\%/Writing 4.4\%/Math 4.8\%). Finally, it is important to point out that these remedial courses add units that are not contributing to the student's major or G.E. requirements, thus adding additional time to their degree completion and additional costs of tuition, books and living expenses.

Table 2. Percentage of Undergraduates in College Remedial Courses by Parents' Educational Attainment

\begin{tabular}{llllll}
\hline & \multicolumn{4}{c}{ Remedial Course Taken Between } & \\
\cline { 2 - 5 } & English & Writing & Math & $\begin{array}{l}\text { Any } \\
\text { Remedial }\end{array}$ & $\begin{array}{l}\text { Ever took } \\
\text { Remedial } \\
\text { Parents' Ed. Attainment }\end{array}$ \\
& & & & & Courses \\
\hline High School Diploma or less & 9.3 & 6.6 & 6.6 & 17.2 & 35.1 \\
Some Postsecondary Ed. & 7.6 & 5.6 & 5.8 & 16.6 & 34.8 \\
Bachelor's or Higher & 6.4 & 4.4 & 4.8 & 13.4 & 27.7 \\
\hline
\end{tabular}

Source: National Center for Education Statistics, 2014, p. 141.

This high rate of remedial coursework, particularly in critical academic areas, is especially poignant considering the number of first-generation college students that are Students of Color within this student population. A significant percentage of Students of 
Color are first-generation college students, and for a portion of them, English is not their first language. Table 3 disaggregates undergraduate students by race/ethnicity and demonstrates that White students had a higher percentage of parents with a bachelor's degree or higher (67.5\%) when compared to Black (11.3\%), Hispanic (14.9\%), and Asian (4.0\%) students, respectively.

Table 3. Percentage of Undergraduates by Race/Ethnicity

\begin{tabular}{llllll}
\hline & \multicolumn{5}{c}{ Race/Ethnicity } \\
\cline { 2 - 6 } Parents' Ed. Attainment & White & Black & Latino & Asian & Other \\
\hline High School Diploma or less & 49.3 & 19.7 & 22.3 & 5.3 & 3.6 \\
Some Postsecondary Ed. & 58.9 & 16.9 & 15.0 & 4.2 & 5.0 \\
Bachelor's or Higher & 67.5 & 11.3 & 14.9 & 4.0 & 4.6 \\
\hline
\end{tabular}

Source: National Center for Education Statistics, 2014, p. 57.

Service-learning pedagogy challenges students and faculty to think outside of the classroom, and provides opportunities for students, faculty, and institutions to create a unique form of meaning and understanding in academic coursework. Additionally, students who take service-learning courses self-report levels of "perceived gains" in "engagement in deep learning" that are $8.5 \%$ higher than students who did not participate in service-learning; service-learning received the highest score of all the High Impact Practices (HIPs) (Kuh, 2008). These HIPs are educationally purposeful activities that integrate college education with experiences that stimulate greater levels of student engagement. However, only $15 \%$ of first-generation college students participate in these activities, even though first-generation college students stand to 
benefit more from the increased levels of "engagement in deep learning" (11\% on a standardized scale) (Kuh, 2008). The pedagogy in service-learning fosters a more personalized and engaging curriculum, which has the potential to ameliorate attrition with first-generation college students.

Service-Learning in Academic Affairs. Service-learning as an institutional practice continues to be an emerging field with many different strands and applications. This dissertation will focus exclusively on service-learning in Academic Affairs as it relates to student success outcomes within various SFSU disciplines. Furthermore, to highlight the academic elements in higher education in the service-learning field, a distinction will be made between course-related service research as informed by the course content and non-course related forms of service research. In particular, the study will explicitly be looking at students who had course-related service that included a community-based project as part of their underlying feature.

Moreover, service-learning programs in higher education are situated within various departments at each school. Currently, 37 percent of colleges have servicelearning under Student Affairs, 40 percent are under Academic Affairs, 8 percent in both, and 6 percent are within the President's office ("Campus Compact," 2014). Therefore, the placement of service-learning at universities dramatically changes the breadth and scope of the project in higher education, either situating it as a curricular activity within Academic Affairs or co-curricular within Student Affairs, which 
dramatically alters the effects of service-learning contribution to the student's academic success.

In academia, the lack of a major or minor in service-learning at universities has left it susceptible to the ebb and flow of school administrations and their commitment to the practice. Nationally the state of service-learning is such that half of all servicelearning directors are full-time, and 37 percent of all service-learning offices have annual budgets (including salaries) below $\$ 99,000$ ("Campus Compact," 2014). These numbers put service-learning institutes and centers at a fiscal, intellectual, and institutional disadvantage, with little to no incentive for scholarship in the field, despite the university's commitment to service in the tenure and promotion process.

However, in a school system that adheres to a specific kind of academic mechanism of tenure and advancement, not having designated scholars and scholarship have been challenging to the support and establish the field. Therefore, the perceptions and stigma in faculty and disciplinary interests in the field are such that, "ServiceLearning is overwhelmingly used by the least powerful and most marginalized faculty (e.g., people of color, women, and the untenured), by the 'softest' and most 'vocational' disciplines and fields (e.g. education, social work), and with minimal exchange value (i.e., tenure and promotion prioritization" (Butin, 2006, p. 475). The lack of institutionalization through a discipline has contributed to the notion that servicelearning is not a rigorous practice and does not contribute to the academic development 
of students and courses. It has been limited to social and emotional development, not academic. Therefore, instead of creating a discipline, some universities have opted to support the service-learning practice through their administrative channels in Academic or Student Affairs, such as with other student support services, study abroad, and learning communities to establish the field.

Despite these institutional challenges, many universities and faculty within various areas of practice understand the importance of experiential learning in their discipline due to the necessity of overall practical experience in their field, which has yielded various courses and outcomes in service-learning courses modeled after them, namely through internship courses through their departments.

\section{Research Questions}

The research questions in this dissertation are:

1. Do first-generation students spanning multiple class standings, who have taken courses with service-learning components, perform better academically than those who have not taken courses with service-learning components?

2. How do first-generation students perceive their service-learning experiences on their academic success?

These two research questions are designed to evaluate how service-learning practices at SFSU are affecting first-generation college students. The case study will employ both 
quantitative and qualitative analysis of data from first-generation students on their experience with service-learning activities.

\section{Conceptual Framework}

Grounded in the work of John Dewey and Jean Piaget, to name a few, the Experiential Learning Model is used as one of the primary foundations for servicelearning in academia (Jacoby, 2014). As Bransford, Brown, and Cocking (1999) state, a Deweyan approach to learning is practiced when students are asked to test class theories and experiment with class content in the real world. Based on the Experiential Learning Model, the service-learning pedagogy is made up of four essential elements: (1) concrete experiences, (2) observation of and reflection on that experience, (3) formation and synthesis of abstract concepts based on the reflection, and (4) active experimentation that tests the concepts in new situations (Jacoby, p. 205). According to Jacoby, within the Experiential Learning Model learning occurs when the cycle of experience, reflection, academic content are repeated, and "learners test their newly developed concepts in concrete experiences" (Jacoby, p. 205). Therefore, the reflection, observation, and experimental components, which are central to this pedagogy, are designed with the intention of leading the students to a deeper understanding of the academic content of their educational experience. In practice, this means that servicelearning is contextualizing the theoretical studies of students with meaningful service projects in the real-world that connects to their major and careers, all while enriching the teaching and learning in the classroom. 


\section{Definition of Key Terms}

The terms used in this study about service-learning courses, first-generation college students, and academic success are as follows:

Service-Learning. For this study, the definition of service-learning will correspond with the National Student Survey on Engagement (NSSE) data set in the analysis. According to NSSE (2017), service-learning is defined as courses at the university that include a "community-based project." Therefore, a course with a community-based project will be synonymous with service-learning courses at SFSU.

First-Generation Student. The survey data used for this study, based on NSSE survey information, identifies a first-generation student when a student's parental or guardian level of education is less than a bachelor's degree (NSSE, 2017).

Academic Success. For the quantitative portion of the study, academic success are defined as follows; (1) first-year end-of-year cumulative GPA and fall-to-fall retention, and (2) cumulative GPA and the number of years to graduation for firstgeneration college students taking at least one service-learning course at SFSU.

High-Impact Practices (HIPs). "High-impact practices, or HIPs, are active learning practices that promote deep learning by promoting student engagement" (Kuh, 2008).

Retention. Retention is the percentage of a given cohort that re-enrolled at the institution from fall to fall. ("US Department of Education," 2014). 
Persistence. According to NCES (2014), "Persistence refers to the act of continuing towards an educational goal (e.g., earning a bachelor's degree)." Therefore, persistence refers to a disposition of a student to continue whereas retention is a measurement of a student returning to school.

Significance of the Study

Research that focuses on the positive outcomes of students participating in service-learning has divergent findings within the different methodologies in the field. Furthermore, more research is needed on first-generation college students taking service-learning courses. The significance of this dissertation analysis on retention is twofold: (1) understanding service-learning as a course-based intervention and (2) retention strategies for first-generation college students at a 4-year university. In particular, due to the breadth and scope of how service-learning is operationalized nationwide, the study will review the gamut of research from within different courses, service projects, empirical case studies, meta-analysis, longitudinal studies, and national survey research, which might not be generalizable to all schools. The case study of SFSU will incorporate various previous research studies, which best apply to the institution to assess the relationship between service-learning and first-generation college student success, considering the resources used at this university.

Research suggests that successful student retention strategies connect pedagogical practices that explicitly integrate students' academic and social college 
experiences (Tinto 1975, 1982). A challenge of student retention strategies, however, is to identify "which types of students in which types of settings" help reduce attrition (Tinto, 1982, p. 699). There is abundant research on the challenges that first-generation college students face in college (Choy, 2001, Chen, 2005, Engle, 2007, NCES, 2014, HERI, 2011, The Pell Institute, 2016). However, there is a need for more research to understand which practices nurture college students psychological and cognitive development within higher education (Pascarella \& Terenzini, 2005), especially for first-generation college students. This dissertation analysis will help address several of these unanswered questions.

Learning communities, service-learning, undergraduate research, first-year experiences, and capstone projects are identified as high-impact practices (HIPs) (Brownell \& Swaner). On a national level, studies on HIPs have identified methods of teaching and learning that can address students' academic engagement and persistence in higher education (Brownell \& Swaner, 2010). Using NSSE data $(n=20,000)$, researchers found that students who participated in one to two HIPs self-report levels of engagement $6.3 \%$ higher than students who did not take part in HIPs, and $12.8 \%$ to $19.8 \%$ when participating in three to four and five to six HIPs, respectively (Kuh, 2008). These educational practices are increasingly being strategically infused into various academic settings in higher education to address challenges with non-traditional students. First-year experiences are especially looking to these teaching strategies since the student's first year is a pivotal time in the student's college career. 
Chapter Two: Literature Review

Introduction

Service-learning is a teaching and learning strategy that intentionally combines lived experiences and civic engagement with college instruction to increase student college integration (Jacoby, 2014). To address the research question, how does servicelearning effect the academic success of first-generation college students, this literature review clarifies what practices in service-learning have positive effects on the persistence and retention of students in higher education. The analysis of the literature offers insight by highlighting the research on service-learning participants in various academic settings and studies. Research that focuses on the positive outcomes of service-learning participants at times has divergent findings within the different methodologies in the field. Even though service-learning features academic and social integration as its primary objective, the impacts on student grades and graduation rates are not well understood and require more research.

The challenge in making sense of the research presented in the literature are the different ways service-learning pedagogy is operationalized and assessed at four-year universities. Understanding the many manifestations of service-learning and tracing back the methods to common academic indicators is an essential first step. In what follows, a review of the existing literature will be presented and summarized in the following areas: (1) the experiential learning model and theories of retention within the conceptual framework, (2) service-learning and academic outcomes, and (3) service- 
learning and personal outcomes (e.g., prosocial academic behaviors). In the following three sections, the study discusses in depth several theoretical constructs that inform service-learning in higher education.

The conceptual framework for this dissertation focuses on the Experiential Learning Model (Dewey, 1938) and service-learning pedagogy, respectively. In higher education, the issues of student persistence and engagement are extensively studied from various disciplinary vantage points. However, contemporary conceptualization of student engagement, according to scholars in the field, is understood in relation to the quality of student involvement in learning activities (Kuh 2009). This scholarship can be traced as far back to the educator John Dewey, who provided the philosophical foundations of the Experiential Learning Model in education in his book, Experience and Education (1938). Furthermore, contemporary literature has built on Dewey's philosophical position by diversifying the research and practice in higher education. In particular, scholars have focused on engagement within the following areas: student involvement (Astin, 1984), social and academic integration (Tinto, 1987, 1993), good practices in undergraduate education (Chickering \& Gamson, 1987), student engagement (Kuh et al., 1991), and experience-based education (Kolb, 1984).

Previous research on service-learning has tended to emphasize the overall positive outcomes of service-learning for participants in higher education. Despite this positive focus, there are contradictory findings on the contributions of service-learning specific to improving retention and graduation rates. Four major categories of academic 
outcomes have been identified in previous research on service-learning including: (1) student learning outcomes in and out of the classroom (Eyler and Giles, 1999, Astin, et al., 2000, Kuh, 2008), (2) the impact of service-learning on GPA and test scores (Strage, 2000, Novak, Markey, \& Allen, 2007, Leimer, et al., 2009, Warren, 2012), (3) the effects of service-learning on retention and persistence (Gallini \& Moely, 2003, Keup, 2006, Bringle \& Hatcher, 2010), and (4) involvement and perception (Lundy, 2007, McKay \& Estrella, 2008, Yeh, 2010). This literature review will discuss the significant categories mentioned above with a special interest on variables that contribute to the academic success of students taking service-learning courses. In what follows, the study will first address the Experiential Learning Model as discussed by John Dewey and David Kolb; this conceptual framework will situate service-learning theory and practices as it relates to the major themes in the literature review.

\section{Conceptual Frameworks}

Education and Experience. In education, using student experiences as the source of knowledge, is a paradigm shift in pedagogy. In positing experience at the center, Dewey wanted to bring the rigor of the scientific method paradigm into philosophical research with a particular emphasis on education. In his book, Experience and Education (1938), Dewey explains learning from experience through the process of reflection, inquiry, and experimentalism (i.e., the scientific method). Dewey states that learning through "reflection includes observation" in practice (1933, p. 102) since for him it is the building blocks for genuine inquiry. For Dewey, academic inquiry, just like 
the scientific method, meant grappling with experience in relentless experimentalism, both in theory and practice. Ideas and their interaction with the real world allow for the type of reflection that make the needed connections for the building blocks of knowledge. Therefore, for Dewey, knowledge without this kind of situated learning and reflection education lacks the rigorous inquiry necessary to address challenges we seek to solve in teaching and learning.

Furthermore, "Reflective Thought" is the central construct that brings the concepts mentioned above together, which according to Dewey had five phases, "Suggestion," "Intellectualization," "the Hypothesis," "Reasoning," and "Testing" (Dewey, 1933, p 107). The first phase of reflective thought speaks to the concept of "suggestion" and points to the ability to consider other courses of action when confronted with a situation in experience, which is described as "the mind leap[ing] forward to a possible solution" (p.107). In reflective thought, when the subject is reflecting on their own experience, a suggestion will manifest itself and as such will inform or guide the theory developed by the participant in considering viable alternatives to the process of inquiry.

The "Intellectualization" phase of the inquiry, according to Dewey, is defining the problem and possible solutions by conceptualizing the different aspects of the problem (or theorizing). He goes on to state that, "an intellectualization of the difficulty or perplexity that has been felt (directly experienced) into a problem to be solved," is formed into the "question for which the answer must be sought" (Dewey, 1933, p.109). 
Therefore, intellectualization is an essential phase because it helps frame the problem and possible solution in the abstract. However, this is just the first step of the process of making sense and meaning of the content learned. Making sense of the issue allows for a conceptualization of the challenge, and it provides a guiding roadmap to the inquiry within situated learning.

The subsequent phase of intellectualization is "The Hypothesis" phase. Dewey situates this notion as the guiding idea based on previous knowledge or observation of the problem. He states, "the use of one suggestion after another as a leading idea," is the Hypothesis since it is used "to initiate and guide observation and other operations in the collection of factual material" (1933, p. 108). It also provides the guiding questions being explored within the conceptual framework and the suggestions of practice within experience, as mentioned above. The "Reasoning" phase, which brings it together conceptually by reflecting on the hypothesis and application of the experience. It is the "mental elaboration of the idea or supposition," according to Dewey (p.109) since it is a part of the inferences of the whole idea. Reasoning, in this sense, allows the learning process to posit various rationales to work through in the testing phase.

The "Testing" phase allows for the experimentation of all the concepts mentioned within the construct of reflective thought. The testing phase enables the inquiry to verify the abstract by observing the problem and solution in the real world. Testing all the steps mentioned above will solidify each one (or disconfirm them) as they prove themselves in the applied setting. However, it is important to point out that 
for Dewey, these aspects of reflective thinking, and learning, are non-linear, and the sequence of these phases are not fixed. Just like the experience, they are mutually reciprocal and continually inform each other in each phase.

The Experiential Learning Model. The scholar, David Kolb, popularized the work of John Dewey and presented a more contemporary look at experience-based learning. In the book, Experiential Learning as the Science of Learning and Development, (1984) David Kolb presents a four-stage model of learning and what we now know as the Experiential Learning Model in contemporary educational literature. The model for Kolb has four components: concrete experiences, observations and reflections, the formation of abstract concepts and generalizations, and the testing implications of concepts in new situations (Figure 1). Kolb's four-stage model is based on Dewey's reflective thinking. However, Kolb's model attempts a more applicable version of the theory compared to the one Dewey presented, and it speaks explicitly to practitioners in the field of education. 
Figure 1: The Experience Learning Model.

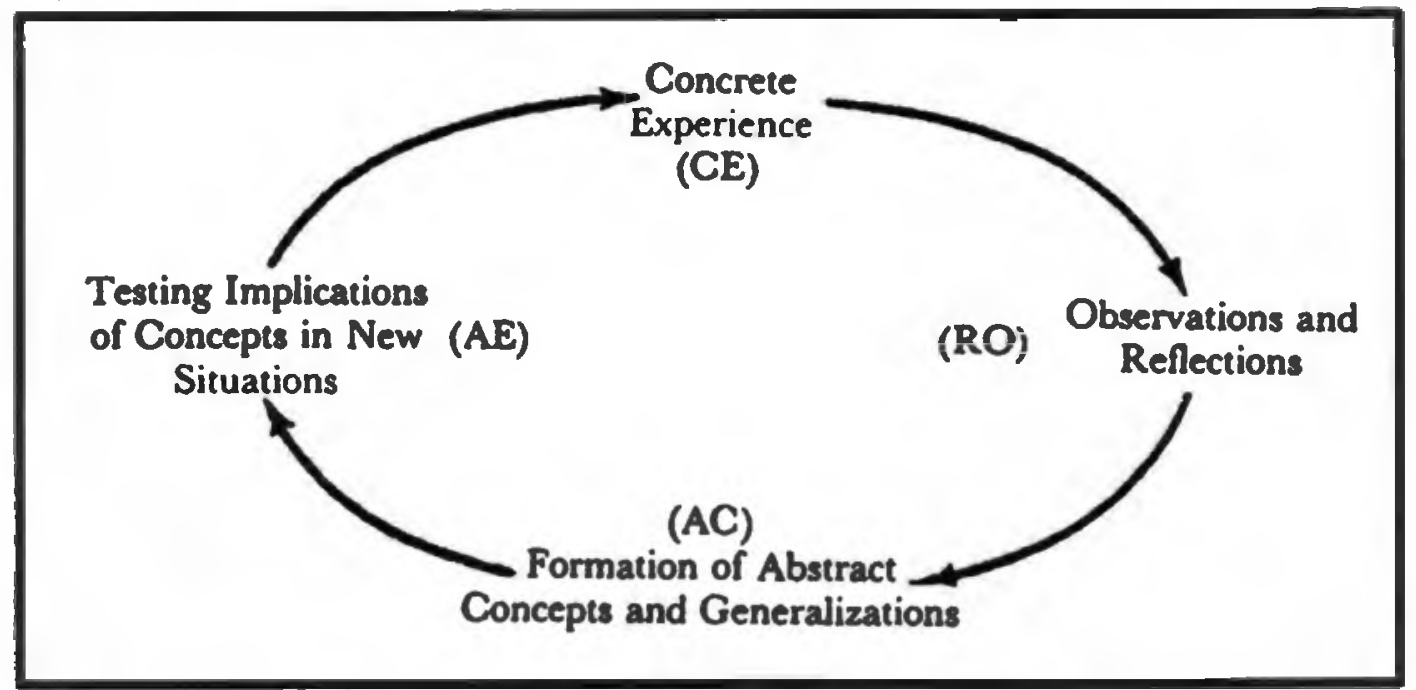

Source: Kolb, D. A. (1984). Experiential learning.

Learning from experience, for Kolb (1984), is when the learner can progress

through these four cycles of knowledge that are on an educational continuum, explicitly connected by specific learning styles. The learning styles between the phases are what make Kolb's experiential learning model different from Dewey's. The first learning style connects Concrete Experiences (feeling) to Observation (watching), which are brought together by the learner with what he calls "Diverging," which is the union of "feeling and watching," since a new experience or a reinterpretation of an existing one happens during this transition. The second connection is from Observation (watching) to Abstract Conceptualization (thinking), and the two are described as "Assimilating," which brings ideas and concepts together to organize a clear explanation of a situation. The third transition is from Abstract Conceptualization (thinking) to Testing Implications (Doing), and it is described as "Converging," where the learner finds 
practical solutions to applied issues. Finally, the transition that brings it all together is the "Accommodating" juncture, since it is the hands-on phase of the learning cycle where the testing happens, and the theories are denied or confirmed.

The experiential learning model presents learning as a process where knowledge creation is a combination of engaging with experience and transforming it (Kolb, 1984). The experiential learning model as expressed by Kolb situates the pedagogical practice that "begins with an experience followed by reflection, discussion, analysis, and evaluation of the experience" (Kolb, 1984), and taps into several learning styles in the process to address various student academic sensibilities. According to Pacho (2015), as it relates to practices in higher education, Kolb explicitly points to "internships, field placements, work-study assignments, structured exercises and role plays, gaming simulations, and other forms of experience-based education as playing a large role in the curricula of undergraduate and professional programs" (Pacho, 2015, p. 10).

In sum, Dewey's philosophy of epistemology connects to his pedagogy, and it also extends to his political philosophy with his conception of community and democracy (Pacho, 2015, Giles \& Eyler, 1994, Kolb, 1984). In other words, the five aspects of reflective thought also connect to solving social problems. It is at this juncture between Dewey's epistemology and social philosophy that service-learning attempts to bring together the academic and social aspects of learning into the classroom. 
Academically, Dewey argues that applied learning and reflection enhances the learning and teaching experience. Socially, situating these applied academic experiences in the real-world develop active citizens fundamentally connected to society. It is this applied learning both in academia and in society that makes Kolb's contemporary articulation of the Experiential Learning Model central to the theory of service-learning in higher education since it provides the quintessential conceptual framework for practitioners in the field. In what follows, the study will look at contemporary theories on retention and student engagement as it relates to academic and social integration contributing to college success.

Theory on Retention. Through the work of Tinto $(1975,1982)$, college integration in academic and social experiences have become a central discourse across various educational practices. In particular, "academic integration," according to Tinto, focuses on the contact the student has with the faculty inside and outside the classroom, the more these points of contact occur, the more academically integrated they become for the student. On the other hand, "social integration" is defined as the connections students make with other peers in a college setting, both inside and outside the classroom. Within this theoretical framework, academic and social integration work in mutual reciprocity in that they are both needed to impact student retention and persistence in a meaningful way. Therefore, according to Tinto, one without the other is insufficient. 
The major premise of integration and engagement as constructs is how to operationalize pedagogical practices that address the student holistically and in their natural settings, as opposed to narrowly conceived one-dimensional retention and intervention strategies. Since the student's efforts and involvement are "critical determinants of college impact, institutions should focus on the ways they can shape their academic, interpersonal, and extracurricular offerings to encourage [more] student engagement" (Pascarella and Terenzini 2005). However, student engagement and retention is not a one-size-fits-all, 4-year universities need to know how to interpret and use these effective educational practices strategically within their various student populations.

Additionally, there are some limitations to this research since many contemporary scholars suggest that Tinto's theory of retention does not go far enough, in particular, when it comes to students of color and culturally appropriate conceptualization of academic and social integration (McCubbin, 2003). The problem with the theory of academic and social integration is that it takes the vantage point of a white, middle class, traditional student perspective and the social capital associated with such an academic trajectory, marginalizing most, if not all, first-generation students that do not fall within this construct (McCubbin, 2003). However, service-learning can help with these limitations of the social and academic constructs by providing pedagogical experiences that are culturally inclusive within the college context. 


\section{First-Generation College Students}

Expectations and Encouragement. Research indicates that students whose parents did not go to college compared to their counterparts have a different experience when it comes to expectations and encouragements (Terenzini et al., 1996). In particular, Terenzini found that meaningful connections between faculty and peers can offset the connections that first-generation students have at home (Terenzini et al.., 1996), which improves the college experience because they are the first professional they connect with in a meaningful way. Therefore, targeted intervention efforts can help mitigate these differences, specifically with student-faculty interactions.

Institutions of higher education have tested several interventions in this regard with various co-curricular strategies. For example, learning communities are especially useful for first-generation college students because they provide the support and encouragement the students need to succeed academically. The academic behavior encouraged through learning communities, infuses a pedagogical practice in the classroom that encourages students to come together to improve their academic interactions with peers and faculty. Learning communities, such as Educational Opportunity Programs (EOP), are staples at many universities across the nation to help nurture the relationship between the first-generation students, faculty, and university student success staff. However, these programs are limited to a cohort of students and require an application and acceptance process, which many times can only address a fraction of the students that need these supports. 
Enrollment Characteristics. The demographics and enrollment characteristics of first-generation students play a crucial part of the student's integration into the college experience, especially when it comes to financial need since many students are from low-income homes and are students of color (Choy, 2001). Financially, first-generation college students have more unmet financial need for school and overall living expenses (Choy, 2001, Chen, 2005). Therefore, in addition to working full-time, first-generation college students borrow more financial aid at disproportionate rates, amassing large amounts of debt. Even when graduating with a bachelor's degree, they are burdened with years of payments, which at times can translate to high default rates (Brookings Institute, 2015). Finally, because the student's income is connected to the families livelihood, the student's needs and hardships are an extension of the families needs and challenges (one cannot be separated from the other), which adds to the fiscal disadvantage of the student. Therefore, work and financial security are always at the forefront of the student's needs for themselves and their families.

Additionally, many first-generation college students do not finish their college careers with a bachelor's degree due to the high dropout rate. Therefore, the educational loan debt becomes even more burdensome. These students find themselves without the benefit of a college degree, yet still have to experience the full brunt of college debt. In a scenario where the student drops out and starts working a low-skilled job, the ratio between the percentage of money owed and the percentage of money earned becomes even more drastic. A college education, where debt is accumulating and where the 
student cannot immediately contribute to the family's income, makes a higher education impossible to justify and leads to many students dropping out (Choy, 2001, Chen, 2005, NCES 2014, Brookings Institute, 2015). This is especially the case when the education the students are receiving does not seem to translate to practical experience or professional development that can help the conditions they find themselves in, and is putting them (and their families) deeper into the hole with debt.

Finally, adding to the financial burden, when comparing the enrollment of firstgeneration college students in many for-profit versus public institutions, about $50 \%$ of students enrolled in the for-profit schools are first-generation college students ("US Department," 2014). The marketing behind these trade schools, among others, many times revolve around a quick and easy way to a professional degree and the income associated with the education, which resonates with first-generation student sensibilities and needs due to their circumstances.

Intervention Efforts. Pre-college and college efforts address issues of encouragement, motivation, access, and effective educational practices institutionalized both in high schools and universities to counteract the lack of academic resources of these students and their families. Programs like Upward Bound, Gear Up, EOP, and other federally funded programs like TRIO are at the center of these efforts. As mentioned above, learning communities, both in high school and college, are one of many popular strategies since it provides wrap-around services to students that include several targetted high-impact practices. For example, learning communities provide a 
first-year experience, cohort educational experience that includes peer social and emotional support. Additionally, career development programs, such as Metro at SFSU, which also immerse the students in their future careers creates a pathway for students academic and professional success. These practices have proven to be fruitful for the students that have taken the program since their success rate has been higher than their counterparts that are not receiving the interventions (Ayala and Striplen, 2002). However, not everyone can have access to these resources since there are limited spaces in these programs.

\section{Service-Learning in Higher Education}

Course-based experiences in service-learning across many semesters can benefit the student's college learning environment, especially for first-generation college students in their first year. Freshmen and senior years for students have been identified as critical points in their college careers; it is when the indicators of retention and graduation are most poignant. However, only $15 \%$ of first-generation college students participate in service-learning even though first-generation college students stand to benefit more ( $11 \%$ on a standardized scale) (Kuh, 2008). In what follows, the literature review will look at service-learning outcomes and address the studies that demonstrate promise in student success including learning outcomes, grades, retention, and student perceptions. 


\section{Academic Outcomes}

Academic Development. Service-learning has been found to increase students' ability to make applied connections in and out of the classroom. For instance, at fouryear universities, service-learning has a statistically significant effect on college students' experience of personal efficacy, awareness of the world, personal values, and engagement in class (Eyler \& Giles, 1999). This is important because this seminal study establishes students' ability to understand complex problems, critical thinking in dealing with complexity, and cognitive development due to the applied experience. Similarly, students' "educational integration," "leadership," and "career readiness" are improved by integrating service-learning in the classroom (Ikeda \& Yee 2000). Four major areas of personal development particular to service-learning include self-efficacy, academic performance (i.e., GPA, writing, critical thinking), values (i.e., activism, racial understanding), and classroom engagement (Astin et al., 2000). A robust comprehension of the subject matter had a dramatic effect on the students' selfperception and subsequent academic commitments. Both the Eyler and Giles (1999) and Astin, et al. (2000) studies carefully analyzed students' academics to understand the critical thinking skills of problem analysis and solutions in the classroom that are unique to the pedagogy of service-learning. The upshot of these foundational studies was that service-learning was found to contain high-quality learning that included course integration through collaboration and experiential learning which positively 
offset the disadvantages generally associated with overall student college disengagement.

Additionally, nationwide studies on high-impact practices (HIPs) have identified methods of teaching and learning that can address students' academic commitment and persistence in higher education (Brownell \& Swaner, 2010). Learning communities, service-learning, undergraduate research, first-year experiences, and capstone projects are identified as HIPs (Brownell \& Swaner). Using the National Survey of Student Engagement (NSSE) data $(N=20,000)$ researchers found that students who participated in 1 to 2 HIPs self-report levels of engagement $6.3 \%$ higher than students who did not take part in HIPs, and $12.8 \%$ to $19.8 \%$ when participating in 3 to 4 and 5 to 6 HIPs, respectively (Kuh, 2008). Service-learning is of particular interest in these findings as it is unique from the rest of these educational practices. Unlike other HIPs, with proper coordination, service-learning can be infused into a broad range of existing curriculum as a set of pedagogical tools complementary to the student's scholarship, career, and major. Also, students who take service-learning courses self-report levels of "engagement in deep learning" and "perceived gains" that are $8.5 \%$ higher than students who did not participate in service-learning; it received the highest score of all the HIPs (Kuh, 2008).

Grades and Test Scores. Research findings on the academic improvements from service-learning are mixed. The service-learning research argues that experiential learning creates positive spaces for students to develop their academic careers through 
experiential learning; however, these improved social and experiential settings, many times, do not directly correlate to better test scores. Nevertheless, positive differences in service-learning still manifest themselves as significant even when GPA cannot account for such social and academic nuances. For instance, despite overall increases in student engagement, grades between service-learning participants vs. non-service-learning participants do not show any statistically significant difference (Strage, 2000, Leimer, et al., 2009). Leimer, Yue, \& Rogulkin assessed the service-learning effects at CSU Fresno where about $10 \%$ of the students participated in a longitudinal study over five years. Consistent with previous studies the service-learning group displayed improvements in classroom discussion and writing as it related to the quality of their experiences. However, the two comparison groups (i.e., service-learning vs. nonservice-learning participants) did not vary in GPA since both the service-learning and non-service-learning students averaged an exact 2.92 GPA over the span of five years. Similarly, Strage (2000) finds that service-learning participation over an academic year had little to no effect on the grades - the service-learning group scored 96.24 and nonservice-learning scored 91 on a standardized test, respectively. In contrast, Strage notes that the advantages of service-learning are most apparent with course content that entail narrative assessments, not "multiple choice" or "factual knowledge."

A better perspective on the effects of service-learning on grades is provided by two comprehensive meta-analyses (Novak, Markey, \& Allen, 2007, Warren, 2012). The meta-analysis conducted by Warren (2012), which included the Strage (2000) study 
mentioned above, found that of eleven quantitative studies, including the nine used in Novak, Markey, and Allen (2007), student outcomes are improved across the board by service-learning participation compared to their controlled groups. All eleven studies reported combine benefits in learning outcomes that demonstrated service-learning had a statistically significant effect $(p=.000)$. The Warren means effect size, similar to Novak, Markey, and Allen, suggest that service-learning does, in fact, increase student learning outcomes $(\mathrm{d}=.332)$, which is slightly lower from Novak, Markey, and Allen's findings ( $d=.424)$, nevertheless, still statistically significant (Warren, 2012). According to both authors, the meta-analysis method provides evidence that service-learning develops skills of critical inquiry in applied settings because it requires the learners to test their newly developed concepts within concrete experiences.

Furthermore, unlike Novak, Markey, and Allen, the Warren study makes an important distinction when parsing out the two primary measuring techniques in the studies, namely, self-reporting (i.e., student perception and dispositions) and "concrete measures" (i.e., exams, assignment scores). Therefore, when Warren analyzed both of the types of data separately, the learning was still positively related in both categories across all studies, namely, self-reports $(\mathrm{d}=.365, \mathrm{p}=.000)$ and "concrete measures" $(\mathrm{d}$ $=.311, \mathrm{p}=.000)($ Warren, p. 58). Furthermore, they yielded no statistical difference when comparing these two types of data with each other (Warren, p. 58). Most significant across both the Novak, Markey, and Allen and the Warren studies was the 
course-based benefits, which were strongest for critical thinking and course comprehension, and subsequently grades.

However, despite the use of grades as a standard and essential marker for student success within higher education, grades are not always the most comprehensive measurement of student progress. Even though there is divergent evidence specifically with the effects of service-learning on GPA and tests, the majority of research highlights promising strategies for students through various practices in service-learning that can lead to greater academic success. College students in their first year often experience academic marginalization and isolation, which affect their levels of college integration (Engle, 2007). Therefore, the literature on academic integration and servicelearning suggests a potential to increase overall academic prosocial behavior for students in higher education. Establishing a sense of belonging and purpose may be a more effective gauge of persistence and overall academic success, especially for alienated non-traditional students in their first year (Chen, 2005).

Retention and Persistence. Service-learning studies for first-year experiences have proven to be particularly informative for research on persistence and retention. Statistically significant distinctions in student social engagement in service-learning are noted by Gallini and Moely (2003), who find that first-year service-learning courses promote a positive effect in student's interpersonal, academic engagement, the perception of academically challenging material, and a better retention outcome, compared to non-service-learning. Service-learning compared to non-service-learning 
increased "overall participation" in the course content, noting that $68 \%$ of the students chose to complete an optional fourth class unit associated with additional service hours (Gallini \& Moely, p. 11, emphasis added). In concordance with the study above, Bringle and Hatcher (2010) point out that infusing service-learning into first-year experiences makes for meaningful course interactions with peers, faculty, and the college environment. In the Bringle and Hatcher study, they found that when comparing service-learning students to non-service-learning students in their intentions to re-enroll, service-learning students' re-enrollment was at a $60.2 \%$ while non-service-learning students were at $24.7 \%$. According to the Bringle and Hatcher study, the re-enrollment numbers were due to the student's self-reported results on the "quality of the learning environment" that was due to the "enrollment [in] service-learning," which had a strong correlation in the study.

Using the Cooperative Institutional Research Program (CIRP) data, Keup (2006) explores the relationship between student retention and three different types of curricular intervention for first-time, first-year students ( $n=19,995)$, namely, within service-learning $(\mathrm{n}=7,818)$, first-year seminars $(\mathrm{n}=8,738)$, and learning communities $(n=2,039)$. An important implication of this study is that students that participated in each one of these high-impact practices were less likely to report feeling isolated and were more likely to interact with faculty and peers in a meaningful way. In particular, the study found that service-learning presented the highest gains in percentage points among the three curricular interventions. However, according to the authors, the 
outcomes were indirect since the activities were outside the classroom. Also, as mentioned earlier, within the service-learning analysis, comparisons produced a statistically significant difference when focusing on service-learning versus nonservice-learning students, namely 14.9 percentage points improvement in prosocial academic behavior (Keup). Moreover, due to the benefits of the prosocial disposition students taking service-learning reported an intent to re-enroll for a second year at an increased rate of 14 percent from non-service-learning students (Keup). The upshot of comparing the effective pedagogical practices above is the distinction among the students involved in the course-based interventions within service-learning since "it proved to be the sole predictor of the intention to re-enroll among the three curricular interventions when they were tested as separate programs" (p. 82).

\section{Personal Outcomes}

Prosocial Academic Behavior. Sourcing genuine student engagement from course material is one of the most challenging things to accomplish with a curriculum;

however, it has been shown that having a more integrated appreciation for the groups of subjects/populations being studied through the course added significant value to the class. In particular, Lundy (2007) evaluated students in various psychology courses on emotional empathy, which used a 33-item scale designed to measure a personal "predisposition to vicariously experience the emotions of others" (p. 23). Qualitative findings of 192 participants suggest that the portion of the students in service-learning felt more empathy compared to the research papers and interview groups in the class, 
with an increase of $76 \%$. Most notable was that engaged students in service-learning performed better than students doing research papers and interview projects in the study, which rose by $40 \%$ and $42 \%$, respectively (Lundy). The study suggests that the success of service-learning in these courses is a function of the need for meaningful education, not necessarily an aversion to rigorous coursework. Herein lies the potential to apply these findings to students in need of genuine experience in the classroom, namely, by finding a sense of purpose and direct application (e.g., work readiness, community-based research) to their education, which can lead to a more natural and authentic academic commitment.

Furthermore, a qualitative study conducted by McKay and Estrella (2008) on first-generation college students illustrates how service-learning positively affects the "academic integration," "social integration," and the "beliefs about accomplishing academic goals" of the students taking a service-learning courses (McKay \& Estrella, 2008). Mckay and Estrella found a linear relationship between the first-generation college students and service-learning variables primarily due to the quality of interaction and communication in the experiential courses. In particular, the study demonstrated that creating service-learning opportunities for students and faculty to interact inside and outside the classroom developed a higher quality of interaction with faculty and peers around experiential learning, and thus the self-reported prosocial academic behaviors. These findings suggest that universities can be strategic with course-based interventions in guidance, support, and self-development that first- 
generation college students need with networks that already exist in the classroom and the community.

The findings on first-year experiences and non-traditional students support how service-learning is valuable in overall integration (i.e., academic, community, interpersonal) and retention for various student populations in need of added academic support networks. Similarly, Yeh, (2010) qualitatively explored the effects of servicelearning on non-traditional college students and low-income students on the academic, social and personal outcomes. Both of these student groups in the study had a similarly positive reaction to experiential learning due to the social context. Interviewing six students, Yeh found that four major themes emerged from the qualitative data: a new understanding of cultural capital, resilience, personal meaning, and critical consciousness (Yeh). Resilience is of particular interest because it speaks to the ability of the student to integrate into school and socially succeed despite the academic challenges. The author states that it is this inherent collaborative nature of civic learning that enables the student to cultivate a meaningful engagement with faculty, community partners, and peers, bolstering their academic and social competence. Also, the resilience defined in the study conveyed a self-sufficiency of the students that comes with meaningful integration and a sense of ownership with the community-based research at hand.

In sum, studies in retention that connect to pedagogical practices that explicitly integrate students in their academic and social experiences have been at the forefront of 
expanding our understanding of the student's path to degree completion. Student persistence and retention varies from group to group since students with particular characteristics benefit from different types of activities and in different types of settings. Therefore, the variation of meaningful engagement into traditional academic practices has been increasing over time, and the literature on effective educational practices reflects that direction in higher education.

\section{Conclusions}

The benefit of service-learning as a pedagogical practice is that it breaks away from the monotony of classroom and textbook only education, which at times can lack engaging educational experiences. Research findings in this area are explicit and show that the experiential learning enhances the quality of the learning environment inside the classroom. The studies in the literature review section find that by counteracting the feeling of isolation and alienation in the new college environment with service-learning experiences, students were able to become more personally and socially resilient in academia. Successful college integration within the student's first year is a definitive point, especially when considering that students are most likely to drop out during this formative time (Engle, 2007).

In concordance with studies in student persistence and engagement, servicelearning shows how student retention connects to pedagogical practices that explicitly integrate students in their academic and social experiences. The central premise of service-learning in higher education is predicated on the idea that the more students get 
feedback and practice collaborative problem-solving in applied settings, the more the student will learn and be prepared to manage complex situations, content, and diverse populations, all of which are necessary to succeed in higher education and beyond. Academic engagement with peers and faculty outside the classroom has pointed to educational practices that can help students perform better in their first year.

After reviewing the literature, there is clear evidence to support that servicelearning would have a positive impact on the academic integration and success of college students. Furthermore, very few studies have exclusively focused on the effects of service-learning on non-traditional students in higher education. These studies bring up the potential implications for institutional research in the form of strategic data on the juncture between service-learning, academic success, and retention. This research will contribute by looking at how academic commitments to higher education are created and transformed through experiences in service-learning with a particular focus on first-generation college students. Moreover, the study can contribute to local practice in the services provided to the students at SF State doing service-learning and the firstyear students that are first-generation. When combining service-learning with first-year experiences it has the potential to increase the academic success, retention, and graduation rates of these non-traditional students.

Furthermore, studies suggest an underlying equity issue with first-generation college students and service-learning that has not previously been explored. "Institutional equity" within service-learning practices can be understood in practical 
terms as equal representation, equal access, and equal impact (Finley \& McNair, 2013). To set equity goals for first-generation college students within service-learning is to envision what fully equitable representation is in practice. Therefore, this study rejects the deficit model of first-generation college students in higher education and seeks ways to understand how the institution can better support first-generation college student experiences with service-learning. 


\section{Chapter Three: Methodology}

\section{Introduction}

The purpose of this study is to determine whether first-generation students who engage in service-learning have better academic outcomes than their counterparts that have not taken service-learning. In particular, this study looks at the impact of servicelearning on freshmen and seniors by looking at the student's grade point average, retention, graduation, and years to degree completion. Also, the study will look at themes within collaborative learning, student-teacher interaction, and reflective and integrative learning. An exploratory mixed-methods approach is appropriate as it includes several separate phases of data collection and analysis that provides a multifaceted way of exploring an issue that is not explicitly addressed in the research. Each step of the research process is designed to best address a specific aspect of the overall research questions below:

1. Do first-generation students spanning multiple class standings, who have taken courses with service learning components, perform better academically than those who have not taken courses with service-learning components?

2. How do first-generation students perceive their service-learning experiences on their academic success?

To address these research questions, secondary data were collected for SFSU students from 1) the National Survey on Student Engagement (NSSE) and (2) the Academic Institutional Research (AIR) Office on campus. According to NSSE, student 
engagement is represented in the NSSE data by two critical features of collegiate qualities; (1) the amount of time and effort students put into their studies, and (2) the number of resources the university deployed to student learning opportunities and curriculum ("Center for Postsecondary Survey," 2016). Therefore, the NSSE data provided the service-learning and first-generation data, and the AIR data provided the (a) grade point average, (b) years to degree, (c) transfer information, (d) retention information, (e) graduation, and (f) high school grade point average. Moreover, interviews were conducted with 20 SFSU students belonging to the following three groups, (1) first-generation college students taking service-learning, (2) non-firstgeneration college students taking service-learning, and (3) first-generation college students not taking service-learning.

Setting

San Francisco State University (SFSU) has institutionalized engagement in several ways - through the establishment and support of its institutes and centers, academic programming, and co-curricular service programs. Its College of Ethnic Studies founded in 1968 "on the principles of community-based research and teaching, student leadership, and activism" is still the only college of its type in the nation. The Cesar E. Chavez Institute studies and documents the impact of social oppression on the health, education, and the well-being of disenfranchised populations. The Center for Research and Education on Gender and Sexuality initiates basic research, educational 
and social policy initiatives regarding the effects of social inequality on sexuality and health. The Institute for Civic and Community Engagement (ICCE) provides opportunities for civic engagement and leadership development for students, faculty, and community members. The Health Equity Institute integrates research, community service, and training programs that address health disparities in the U.S. ("Institute," 2014).

For twenty years, service-learning has been an integral part of SFSU's efforts to expand course offerings to enhance student learning. The service-learning program is at the heart of what the ICCE does, assisting faculty in the development and delivery of Community Service-Learning (CSL) courses and building and supporting partnerships with community-based and civic organizations ("About Us," 2017). Service-Learning has been embraced by faculty in all seven of the University's colleges, with 46 departments offering students 200 service-learning courses ("Institute," 2014). Since 2004, SFSU has been one of a few universities nationwide to include CSL credit and volunteer hours on student's official transcripts. In 2006, SFSU was one of only 62 U.S. colleges and universities selected by the Carnegie Foundation for the Advancement of Teaching for the New Community Engagement Classification in both the Curricular Engagement and Outreach \& Partnerships categories. The designation recognized the university's substantial commitment to "teaching, learning, and scholarship that engage 
faculty, students, and community in mutually beneficial and respectful collaborations." SFSU has once again received the 2015 Carnegie reclassification ("Institute," 2014).

Experientia Docet. "Experience Teaches" is the motto of SFSU, which is based on its origins of being a teacher-training college but has continued because it also embodies the universities commitment to community and civic engagement. San Francisco State University is a renowned CSU university, a premier public urban university in service, service-learning, and civic engagement, which focuses on involved collaborative partnerships with the city and region. The university, at one point, had on its campus the national directors of leading programs in the field, namely, Jumpstart (a teacher training program), America Reads (a service-learning tutoring program) and Campus Compact the leading national organization that provides the intellectual advocacy work for service-learning within higher education nationwide. Therefore, service, service-learning, and civic engagement and the application of university resources to community issues a campus hallmark.

As of 2016, the service-learning program has been permanently moved from the College of Health and Social Sciences (HSS) to the Division of Undergraduate Education and Academic Planning (DUEAP) and reports directly to the Dean of DUEAP, who oversees undergraduate curriculum, assessment, advising, and high impact programs at the University. Therefore, the most recent promotion for the service-learning program once again affirms the University's commitment to enhancing 
the students' educational experiences campus-wide and across disciplines through service, service-learning scholarship, and civic engagement opportunities.

Therefore, the service-learning program needs to be re-evaluated to meet the needs to align itself with the university strategic plan and Graduation Initiative 2025, especially for non-traditional students. Service-learning features academic and social integration as its primary goal. However, despite the various service-learning outcomes across the curriculum, the impacts on first-generation college students are not well understood and require more research, which is composed of $37.7 \%$ of the first-time freshmen enrolled in 2017 ("San Francisco State," 2018). In particular, at SFSU service-learning has been positioned within the university to contribute to the student's academic success. Thus this study will explore whether co-curricular experiences in service-learning across multiple semesters can benefit the students' academic success, especially for first-generation college students at SFSU.

\section{The Quantitative Data}

This study combines data from the 2014 and 2017 NSSE data and SFSU's Academic Institutional Research (AIR) school data to explore first-generation college students' academic success at SFSU. The NSSE dataset provided variables for the generational status of students, and the level of service-learning participation for survey participants. The AIR school data provided additional variables for the GPA, retention, and graduation statuses specific to students at SFSU who also took the NSSE survey in 
2014 and 2017. When combined, these data sets have an $\mathrm{N}=4,160$ freshmen and senior SFSU students. Additionally, it is important to note that no one student participated in both years of the NSSE survey. The NSSE datasets (for 2014 and 2017) are designed to survey freshmen and senior students only. Freshmen in both NSSE survey years represent $27 \%$ of all freshmen surveyed. Senior students, on the other hand, represent $73 \%$ of their respective senior class. Overall, together, freshmen and seniors in both NSSE samples represent about $15 \%$ of the overall SFSU student population for both years.

It was additionally essential to identify patterns in the generational status, racial background, and gender of NSSE survey participants included in this case study's sample. Exactly $9 \%$ of freshmen and $24 \%$ of seniors included in the NSSE sample can be classified as first-generation students. NSSE identifies a first generation student as a student who has no parent or guardian who has attained a bachelor's (see Chapter 1, p 25). Students who have at least one parent, or guardian, that has attained a bachelor's degree are not considered a first-generation college student. Additionally, it is important to note that the racial composition of the NSSE sample is $26 \%$ Asian, $5 \%$ Black, $24 \%$ Latino, $23 \%$ White, and $22 \%$ other. These sample numbers are representative of the general university numbers, which have the student populations at $28 \%$ Asian, $6 \%$ Black, $38.4 \%$ Latino, and 22\% White for the major groups considered ("San Francisco State," 2018). Finally, $60 \%$ of the NSSE survey participants are female, and $40 \%$ are 
male, which is also consistent with the university numbers of $57 \%$ female and $43 \%$ male, respectively.

For the first statistical analysis, survey participants were divided into four comparison groups, namely, first-generation student taking service-learning, non-firstgeneration college student taking service-learning, first-generation college student with not service-learning experiences, and non-first-generation students with no servicelearning experience, to analyze better the nuanced intersection between firstgenerational status and service-learning participation as it relates to academic success. Participation in service-learning is measured by the courses a student has taken that included community-based projects as part of the curriculum. Therefore, students in the sample are considered participants of service-learning when they had identified as taken at least one service-learning course (see Chapter 1, p 25). Additionally, achieving academic success measured as, (1) freshmen retention into the second year, cumulative grade point average, and (2) senior years to degree completion, cumulative grade point average, and graduation.

Furthermore, the four comparison groups were used to produce four variables that combined first-generation status and service-learning participation for freshmen and seniors separately. The first group (the primary reference group) includes participants with two parents who did not attain a bachelor's degree, and have taken at least one service-learning course (FGCS\&SL). The second group includes participants 
who had a parent attain a bachelor's degree, and who also participated in at least one service-learning course (NFGCS\&SL). The third group includes participants with two parents who did not attain a bachelor's degree, and who took no service-learning courses (FGCS\&NSL). The final group includes participants who had a least one parent attain a bachelor's degree, and did not take any service-learning courses (NFGCS\&NSL). Table 4 provides basic descriptive statistics for the group sampled in this case study's statistical analysis. 
Table 4: Frequency, Percentages, and Means - Freshmen and Seniors by Comparison Groups

\begin{tabular}{|c|c|c|c|c|c|c|c|c|c|c|c|c|c|c|c|c|}
\hline \multirow{3}{*}{$\begin{array}{l}\text { Service-Learning } \\
\text { Yes }\end{array}$} & \multicolumn{4}{|c|}{$\begin{array}{c}\text { First-Gen \& } \\
\text { Service-Learning }\end{array}$} & \multicolumn{4}{|c|}{$\begin{array}{l}\text { Non-First-Gen \& } \\
\text { Service-Leaming }\end{array}$} & \multicolumn{4}{|c|}{$\begin{array}{l}\text { First-Gen \& no } \\
\text { Service-Leaming }\end{array}$} & \multicolumn{4}{|c|}{$\begin{array}{l}\text { Non-Firsl-Gen \& no } \\
\text { Service-Leaming }\end{array}$} \\
\hline & \multicolumn{2}{|c|}{$\begin{array}{c}\text { Freshmen } \\
n=264\end{array}$} & \multicolumn{2}{|c|}{$\begin{array}{c}\text { Senior } \\
\mathrm{n}=792\end{array}$} & \multicolumn{2}{|c|}{$\begin{array}{c}\text { Fr } \\
=124\end{array}$} & \multicolumn{2}{|c|}{$\begin{array}{c}\text { Seniors } \\
\underline{x}=599\end{array}$} & \multicolumn{2}{|c|}{$\begin{array}{c}\text { Fuehno } \\
=179\end{array}$} & \multicolumn{2}{|c|}{$\begin{array}{c}\text { Senior } \\
\mathrm{y}=420\end{array}$} & \multicolumn{2}{|c|}{$\begin{array}{c}\text { Freshmen } \\
=-14\end{array}$} & \multicolumn{2}{|c|}{$\begin{array}{c}\text { Senior } \\
\mathrm{a}=387\end{array}$} \\
\hline & 264 & $60 \%$ & 792 & $65 \%$ & 124 & $46 \%$ & 599 & $61 \%$ & & & & & & & & \\
\hline No & & & & & & & & & 179 & $40 \%$ & 420 & $35 \%$ & 143 & $54 \%$ & 387 & $39 \%$ \\
\hline \multicolumn{17}{|l|}{ Gender } \\
\hline Male & 139 & $31 \%$ & 460 & $38 \%$ & 101 & $38 \%$ & 421 & $43 \%$ & 56 & $31 \%$ & 178 & $42 \%$ & 48 & $34 \%$ & 168 & $43 \%$ \\
\hline Female & 304 & $69 \%$ & 752 & $62 \%$ & 165 & $62 * 6$ & 565 & $57 \%$ & 123 & $69 \%$ & 242 & $58 \%$ & 95 & $66 \%$ & 219 & $57 \%$ \\
\hline Total & 443 & $100 \%$ & 792 & $100 \%$ & 267 & $100 x$ & 986 & $100 \%$ & 179 & 10096 & 420 & $100 \%$ & 143 & $100 \%$ & 387 & $100 \%$ \\
\hline \multicolumn{17}{|l|}{ Ethnicity } \\
\hline Asian & 75 & $35 \%$ & 269 & $42 \%$ & 37 & $39 \%$ & 165 & $38 \%$ & 54 & $35 \%$ & 104 & $31 \%$ & 35 & $35 \%$ & 77 & $30 \%$ \\
\hline Black & 7 & $3 \%$ & 43 & $7 \%$ & 6 & $6 \%$ & 26 & $6 \%$ & 7 & $5 \%$ & 21 & $6 \%$ & 10 & $5 \%$ & 13 & $5 \%$ \\
\hline Latino & 111 & $52 \%$ & 230 & $36 \%$ & 17 & $18 \%$ & 77 & $18 \%$ & 76 & $49 \%$ & 96 & $28 \%$ & 18 & $49 \%$ & 50 & $20 \%$ \\
\hline White & 19 & $9 \%$ & 104 & $16 \%$ & 35 & $37 \%$ & 170 & $39 \%$ & 19 & $12 \%$ & 116 & $34 \%$ & 19 & $12 \%$ & 116 & $45 \%$ \\
\hline \multicolumn{17}{|l|}{ Cumalative GPA } \\
\hline Mean & 2.99 & & 3.15 & & 3.10 & & 3.20 & & 3.16 & & 3.18 & & 3.08 & & 3.15 & \\
\hline SD & .633 & & .516 & & .710 & & .525 & & .647 & & .533 & & .583 & & .539 & \\
\hline \multicolumn{17}{|l|}{ Retention Rate } \\
\hline Yes & 234 & $89 \%$ & & & 104 & $84 \%$ & & & 155 & $87 \%$ & & & 117 & $82 \%$ & & \\
\hline No & 30 & $11 \%$ & & & 20 & $16 \%$ & & & 24 & $13 \%$ & & & 26 & $18 \%$ & & \\
\hline Total & & & & & & & & & & & & & & & & \\
\hline \multicolumn{17}{|l|}{ Graduation } \\
\hline Yes & & & 634 & $80 \%$ & & & 497 & $83 \%$ & & & 309 & $74 \%$ & & & 293 & $76 \%$ \\
\hline No & & & 158 & $20 \%$ & & & 102 & $17 \%$ & & & 111 & $26 \%$ & & & 94 & $24 \%$ \\
\hline Total & & & 792 & $100 \%$ & & & 599 & $100 \%$ & & & 420 & $100 \%$ & & & 387 & $100 \%$ \\
\hline \multicolumn{17}{|l|}{ Years to Degree } \\
\hline Mean & & & 3.7 & & & & 3.8 & & & & 4.1 & & & & 3.9 & \\
\hline $\mathrm{SD}$ & & & 1.98 & & & & 2.39 & & & & 3.66 & & & & 2.38 & \\
\hline \multicolumn{17}{|l|}{ Transfer } \\
\hline Yes & & & 569 & $73 \%$ & & & 387 & $68 \%$ & & & 325 & $78 \%$ & & & 256 & $68 \%$ \\
\hline No & & & 217 & $27 \%$ & & & 182 & $32 \%$ & & & 92 & $22 \%$ & & & 121 & $32 \%$ \\
\hline Total & & & 792 & $100 \%$ & & & 569 & $100 \%$ & & & 417 & $100 \%$ & & & 377 & $100 \%$ \\
\hline
\end{tabular}

Source: 2014 and 2017 NSSE Survey, and 2017 SFSU AIR Student Data. 
It is important to note in the table above that the reference group, FGCS\&SL, includes 264 freshmen and 792 seniors (a combined total of 1,056 students) that participated at least one service-learning course. Additionally, precisely 599 students did not attend service-learning courses. The second comparison group, NFGCS\&SL, consisted of 124 freshmen and 600 seniors, 723 participated in service-learning and 387 did not do service-learning. The third comparison group FGCS\&NSL includes 179 freshmen and 420 seniors, 599 participants did not participate in service-learning in this group. Finally, NFGCS\&NSL had 530 participants, which was the group that was composed of non-first-generation student and did not take service-learning in the study.

It is important to point out that 2,102 of the senior participants in the NSSE survey are seniors that transferred to SFSU, and $40 \%$ of these seniors in this sample are first-generation college students that transferred to SFSU. Both transfer and nontransfer seniors will be included in the analysis. This trend in transferring is consistent with the overall trend at SFSU where a third of the students also transfer as juniors from local community colleges in the Bay Area (AIR, 2018). Additionally, according to NCES (2015), 40\% of first-generation students (nationwide) attend 2-year institutions compared to $20 \%$ who directly enroll in 4-year public universities. Due to the high percentage of the first-generation student that start their college careers in 2-year institutions and then transfer out, the study has included transfer status as a variable for seniors in this analysis. 
In addition to the attention on transfer status in this case study, full-time/parttime status for the 718 freshmen, and 1,666 seniors was also considered. It is essential to include a measure of full-time/part-time status in this statistical analysis because of the difference in time and experience. However, even though 15 freshmen and 568 seniors reported having a "part-time status," they are still included in the firstgeneration category because part-time student status has been shown in research to be an integral part of the first-generation experience (see Chapter 1). Therefore, both fulltime and part-time participants were included in the final analysis but analyzed separately in their respective freshmen and senior groups. Unlike the part-time status for seniors, which was about a third of the total group, the frequency of part-time status was in the minority for freshmen, which amounted to only $2 \%$ of the total freshmen sample. However, when controlling for transfer status, no significant difference was discovered when analyzing the dependent variable that looked at years to degree for senior participants. Table 4 presents the transfer information for the seniors in the corresponding groups in the study.

\section{The Statistical Plan Analysis}

A primary goal of this case study is to examine how membership in any of the four comparison groups discussed above produce a statistically significant difference on several key dependent variables (cumulative GPA, and years to degree). Analysis of Variance (ANOVA) ANOVA is necessary when comparing the means of three or more 
groups, which was the case in this study for GPA and years to degree. Therefore, the ANOVA is an appropriate method for addressing this primary goal. Furthermore, one of the assumptions of ANOVA is that the dependent variable should be a scale level of measurement. Both dependent variables (cumulative GPA, and years to degree) are measured as scale variables which satisfy this assumption for ANOVA difference in means and variation among groups.

The secondary goal of this case study was to determine how membership in any of the four comparison groups held statistically significant relationships with several key dependent variables (graduation, and retention). Additionally, to better examine the relationship with Chi-Square analysis, an additional variable was created that combined all comparison groups into a single category identified as, "ALL.GROUPS." Creating this new variable (ALL.GROUPS) allowed us to explore better the intersections of firstgeneration status and service-learning participation and their relationship to the dependent variables (freshman retention, and senior graduation). Furthermore, because one of Chi-Square's assumptions is that the variables being analyzed must be measured at the nominal level, this test is also appropriate to analyze this data.

\section{The Qualitative Data}

Data for the qualitative analysis includes 20 in-depth interviews with undergraduate students from SFSU collected during spring 2017. Participants were recruited using both snowball and purposive sampling to ensure that a diverse sample 
regarding class standing, majors, and departments at each college. All 79 servicelearning courses taught at SFSU in the spring 2018 received an email and flyer about participating in the study (Appendix D). Furthermore, the sample was strategically recruited to ensure that participants who fit the criteria of having the first-generation status and had service learning participation.

For the qualitative portion of this mixed-method study, students who did not identify as first-generation, and who did not take a service-learning course (NFGCS\&NSL) were not included in the qualitative sample. The rationale for excluding these students is because this portion in the analysis is primarily interested in exploring first-generation student experiences. Thus, NFGCS\&NSL students (who were included in the quantitative analysis) are not included in this part of the qualitative analysis.

Overall, participants ranged from ages 18 to 29 , and 16 out of the 20 participants were female ( $80 \%$ of the overall sample). Furthermore, 5 students were freshmen, 10 students were seniors, 3 students were juniors, and 1 student was a sophomore. Ten participants are Latino, three are Asian, 3 are African American, 3 are White, and 1 student is of mixed heritage (Black and Jewish). Table 5 below provides the information for the student's majors, ethnicity, class, and the number of service-learning courses taken in college. Furthermore, Table 5 also shows us that there were ten students in the 
primary group (FGCS\&SL), 5 students categorizes in the second group (NFGCS\&SL), and also 5 students in the third group (FGCS\&NSL).

Furthermore, Table 5 also illustrates that the sample consists of undergraduates from fourteen different majors and all six colleges at SFSU. As stated before, the sampling procedures were purposeful in recruiting participants from all the different colleges to produce a more representative sample of the various student experiences in service-learning across various disciplines. However, the College of Liheral Studies and Creative Arts was oversampled with 10 participants. The College of Science and Engineering has 4 students, the College of Human and Social Sciences has 3 students, and the rest of the sample consists of students from various majors such as the College of Education (2), College of Ethnic Studies (1) and the College of Business (1). Additionally, among the first-generation college students included in this sample, 5 are Liberal Studies majors (a major that focuses on teacher education), 2 are nursing students, 1 is a Psychology major, and 1 is an education major. 
Table 5. Student Participants Characteristics by Comparison Groups

\begin{tabular}{|c|c|c|c|c|}
\hline Name & Ethnicity & Major & Class & \# SL \\
\hline \multicolumn{5}{|l|}{ FGCS\&SL } \\
\hline 1) Alejandra & Latina & Communications & Senior & 2 \\
\hline 2) Montanah & Mixed & Liberal Studies & Senior & 1 \\
\hline 3) Lucero & Latina & Political Science & Senior & 3 \\
\hline 4) Josephina & Latina & Liberal Studies & Senior & 2 \\
\hline 5) Alejandro & Latino & Psychology & Junior & 2 \\
\hline 6) Kylie & White & English Education & Senior & 2 \\
\hline 7) Franco & Latino & Political Science & Senior & 1 \\
\hline 8) Maria & Latina & Nursing & Freshmen & 1 \\
\hline 9) Melanie & White & Nursing & Freshmen & 1 \\
\hline 10) Krysi & Asian & Creative Writing & Freshmen & 1 \\
\hline \multicolumn{5}{|l|}{ NFGCS\&SL } \\
\hline 11) Stephanie & Latina & Spanish \& English & Senior & 2 \\
\hline 12) Emily & White & Sociology & Senior & 1 \\
\hline 13) Tiara & Black & Creative Writing & Senior & 1 \\
\hline 14) Jasmin & Black & $\mathrm{CAD}$ & Senior & 2 \\
\hline 15) Adriana & Latina & Latin@Studies & Junior & 2 \\
\hline \multicolumn{5}{|l|}{$\underline{\text { FGCS\&NSL }}$} \\
\hline 16) Miguel & Latino & Biology & Sophomore & 0 \\
\hline 17) Thomas & Black & Business & Junior & 0 \\
\hline 18) Kimberly & Asian & Biology & Senior & 0 \\
\hline 19) Zulema & Latina & Architect & Junior & 0 \\
\hline 20) Vanessa & Latina & Biology & Freshmen & 0 \\
\hline
\end{tabular}

Plan of Analysis

Participants were recruited from SFSU service-learning courses and were explicitly asked to focus on their experience as it related to their first-generation status and/or service-learning experiences (depending on the group they identified with). The 
researcher then coordinated with each of the respondents that had agreed to participate in the 30 to 45 -minute interview session. During the interview process students were informed of the following: (1) the description and purpose of the study; (2) the incentive structure for participating in the study (e.g. gift certificate); (3) explanation of criteria for participation, which required first-generation status and/or service-learning participation (and the process to opt out); and (4) instructions on how the students' narrative would be used in the study, including their anonymity.

During the interview, participants from the FGCS\&SL and NFGCS\&SL were asked 23 questions, which were parsed out into 6 significant sections regarding their service-learning experience. The questions were further divided into several sections that address the various aspects of the participants' college careers. The first set of questions were intentionally broad and asked the students the circumstances that led them to come to the university in the first place and the reasons they decided to take service-learning courses. The next set of questions asks the students about their perceptions of the service-learning courses before taking them. Then, the students were given questions about the differences between traditional courses and service-learning courses and the types of reflections or assignments that made each of them unique and/or different. Furthermore, it explicitly asked them about the quality of interactions with peers, faculty, and community partners, which are vital people in the learning process in these courses. Finally, the participants were given questions about their perceived academic success specific to themes of retention, collaborative learning, 
interactions with key people at the university, and graduation, all of which were conceived with the major strands in the literature review in mind. In particular, the key factors influencing first-generation college students in the literature were also considered, such as expectations, encouragement, interventions, and persistence. Appendix B provides the questions asked in the interviews, and it is broken down into the categories and themes mentioned above.

For the first-generation participants that did not take a service-learning course (i.e., FGCS\&NSL) a separate set of questions were given to the participants. Instead of focusing on the binary between service-learning and none service-learning experiences, these set of questions focused on the dichotomy between "good" versus "bad" courses, according to the student experiences. The point of these questions was to bring out pedagogical practices that students valued, and were perceived by them as effective educational practices according to their experiences in college. These non-servicelearning questions attempted to directly mirror the service-learning questions to be as consistent as possible to the intent of the study, which is what effective educational pedagogies impact student success.

Therefore, akin to the previous set of questions these participants were asked the circumstances that led them to come to the university and the reasons they evaluated a class as "good." The students were given questions about what made these classes "good" or "bad" and the types of assignments that made each of these courses unique or different. Furthermore, it explicitly asked them about the quality of interactions with 
core people in their learning environment such as peers and faculty, who are critical people to their academic success. Finally, the participants were given the questions about their perceived academic success specific to their persistence and preparation at the university and graduation as it related to the good classes they were taking. Appendix $\mathrm{C}$ provides the questions asked in these interviews, and it is also broken down into the categories and themes mentioned above.

The researcher used a YouTube closed caption service, which is a free service for all videos on YouTube through their accessibility feature, transcribed the interviews. The audio files of the interviews were converted into a video file and uploaded as a private video on YouTube; within 15- to 30 -minutes the system then automatically generated the transcription of the closed caption text in the video. Once the system generated a closed caption document of the interview, it produced a downloadable file that can be converted into a Word document. The narrative on the Word document was edited and reviewed for mistakes by playing the original recording as a close reading of the document was being conducted. Any edits are then made to reflect the exact wording of the interview and sections are created to divide the interviewer and interviewee and to identify the questions and original themes. Finally, once the transcription of the interview was completed, the video file was removed from YouTube, and all private information related to the interviews was deleted from all cloud services. 
For this qualitative section of the study, a thematic analysis approach was used to identify the themes related to student success. As defined in chapters 1 , the thematic analysis works around the high-impact practices, also mentioned in the literature, that are active learning practices that promote deep learning by promoting student engagement. The data were coded using a multi-tier process that included the use of the software program Atlas.ti. The first round of coding identified general keywords and phrases that displayed prosocial academic behaviors related to their course experiences. These phrases, keywords, and narratives accounted for the references to experiences that implied academic success. The second round of coding identified types of student engagement informed by NSSE engagement indicators (see table 6). This coding produced several significant categories across all the groups in the study. The final round of coding counted the number of keywords, phrases, and narratives that related to the NSSE themes across the various comparison groups as they spoke to the academic success themes mentioned in the quantitative section.

Table 6. NSSE Themes and Engagement Indicators

\begin{tabular}{|l|l|}
\hline $\begin{array}{l}\text { Lollaborative } \\
\text { Learning }\end{array}$ & $\begin{array}{l}\text { Student collaboration is identified as engaging in class or group } \\
\text { project, either by explaining the material to others or by asking } \\
\text { questions about the content. }\end{array}$ \\
\hline $\begin{array}{l}\text { Student-Teacher } \\
\text { Interaction }\end{array}$ & $\begin{array}{l}\text { Meaningful engagement with faculty or staff by discussing career } \\
\text { plans, schoolwork, and academic performance. }\end{array}$ \\
\hline $\begin{array}{l}\text { Reflective \& } \\
\text { Integrated } \\
\text { Learning }\end{array}$ & $\begin{array}{l}\text { This concept takes into account how students made connections } \\
\text { with their prior experience and knowledge, and re-examined their } \\
\text { views on social issues by accounting for diverse perspectives in and } \\
\text { outside of the classroom. }\end{array}$ \\
\hline
\end{tabular}




\section{Ethical Considerations and Protection of Subjects}

Confidentiality of information is of the utmost importance since documentation of raw data always comes with the potential risk of exposure at all levels of the research process. The first step of maintaining confidentiality is to keep the data in a safe place where only the researcher has access to it with the encryption (if needed) of the information and pseudo names for all the participants. However, for this case study interview, participants were not asked to face risks beyond those they encountered in everyday conversation. Nevertheless, the participants were informed that they did not have to answer uncomfortable questions and that they could exclude themselves from the interview at any point of the research process. A consent form was read to them that informed the participants of the study and the interview protocol, which provided full disclosure of the process and made their rights explicit as a participant with contact information for the SFSU IRB office. Finally, a part of the consent form was designated to include information about how to be removed from the study if they choose not to participate after the interview had been concluded.

\section{Internal Validity}

The data collected in the first phase consisted of responses acquired from the 2014 and 2017 NSSE questionnaires, which met the conditions for "valid self-reports." According to NSSE, the students were provided questions that were (a) clearly stated, (b) referred to students recent activities, and (c) required thoughtful responses ("National Survey," 2017). The engagement indicators used to assess educational 
practices require student self-reports since it is often the only source for the engagement data. For example, the engagement indicator focused on collaborative practices that necessitate student self-reports on the amount of time and the different people (e.g., classmates, faculty) they worked with on any collaborative project. The engagement indicators in the survey will be scored and interpreted on a one through four scales, namely, $1=$ Never, 2 = Sometimes, $3=$ Often, and $4=$ Very Often. Finally, unlike the self-reports, the GPA, retention, and graduation information for each of the NSSE students in the data set was provided by SFSU and is represented as the institutional record of the student's' academic standing at the university.

In the second data collection phase, the internal validity of the transition from quantitative to qualitative frameworks was addressed by including a subset of the NSSE engagement indicators into the interview session itself to provide context to the subsequent interview (e.g., teacher-student interaction, collaborative learning). The transition from the survey and interview themes allowed for the most continuity, and it allowed the interviewer to further probe into the themes in the initial NSSE survey. The interview portion is set up to directly complement the NSSE themes and engagement indicators as presented in the survey, which was designed to maintain the validity of the interviews in relation to the questionnaire.

The third and final data analysis phase maintains its validity, in part, from the continuity provided by the instrumentation used from the transition of the first to the second phase, as mentioned above. Additionally, both the questionnaire survey data and 
interview questions were guided by NSSE to complement each other and to provide validation from one data set to the next, and vice versa. It allowed for clarifying and follow-up questions on the initial survey, engagement indicators, and individual items in the service-learning institutional data. Therefore, the instrumentation and analysis was integrated from the initial design and explicitly brought together through the interview phase to strengthen its validity, both in content and process.

\section{External Validity}

As a case study, the research was primarily designed for internal use at the ICCE and focused on SFSU students and the services the university provides service-learning opportunities in academic settings unique to this institution. Therefore, the goal of the case study was less about generalizing to other schools and more about providing a rich context of first-generation college students' experiences at SFSU. For example, at SFSU, service-learning has been embraced by faculty at all seven of the University's colleges, with 46 departments offering students 200 service-learning courses ("Institute," 2014). Nevertheless, these case study observations can be used to recreate a parallel analysis depending on the conditions of other institutions even when it might not be able to be directly generalizable in every case. The case study, as any case study, can still provide a framework on a case-to-case basis.

Finally, another aspect that makes the case study of SFSU unique is its College of Ethnic Studies department, which is the only one in the nation and has servicelearning as a graduation requirement. When combined with the school's $25 \%$ Latino 
student population, many of which are first-generation, it can affect the generalizability of the case study results. To mitigate these factors in the analysis the study intentionally selected first-generation college student interviews that represented various departments and reflected the different majors proportional to the NSSE quantitative data. 


\section{Chapter Four: Report of Finding}

\section{Overview}

The guiding research question for this dissertation asks: do first-generation freshmen and senior students who have taken courses with service-learning components perform better academically than those who have not taken service-learning? To address this research question, this exploratory case study uses a mixed methods approach to assess the intersection of service-learning, first-generation status, and student academic success at SFSU. The mixed-methods approach utilized in this case study's collection and analysis of data is designed to identify key characteristics among first-generation students that are indicative of college success and higher levels of student engagement.

This chapter presents key findings in three sections. The first section breaks down the statistical analysis and presents key quantitative findings related to this dissertation's guiding research question mentioned above. The second section in this chapter addresses the qualitative analysis and findings related to the following research question: how do first-generation students perceive their service-learning experiences on their academic success? Additionally, this second section presents key findings organized as three major themes resulting from in-depth interviews with participants at SFSU. These major themes speak to academic success including, collaborative learning, student-teacher interaction, learning strategies, and quality of interactions. Furthermore, 
this qualitative analysis highlights elements of service-learning engagement and the connection to participants' persistence and professional development.

Finally, the third section in this chapter provides a discussion that considers both quantitative and qualitative findings, academic indicators, and the conceptual framework applied in this case study to examine the proposed research questions.

\section{Quantitative Analysis}

\section{Research Question \#1.}

The quantitative data addresses the research question: Do first-generation freshmen and senior students who have taken courses with service-learning components perform better academically than those who have not taken service-learning? The question examines the first-generation status and service-learning participation in regards to freshmen and senior college success (as measured by GPA and years to degree). Specifically, they address how both freshman and seniors have attended their university for different lengths of time, and under differing circumstances pertaining to their class standing. Due to these differences in time enrolled at the university, and circumstances related to their class standings as either freshmen or seniors, this case study separates the statistical analysis for freshmen and seniors. This way the study can better understand how the measures of academic success operate differently for freshmen and seniors. 
This study uses freshmen's first-year fall cumulative GPA because participants completed the NSSE survey during the spring semester and not after. Measuring the statistical difference that various combinations of first-generation status and servicelearning participation have in regards to first-year fall GPA for freshman is meaningful because we can narrow the impact to a particular time and place for the first-year freshmen. This is especially true when analyzing GPA and retention. However, it is also possible that service-learning participation has a potential effect that takes time to influence all aspects of the students' academic success beyond grades and retention. For example, improvements in collaborative learning and better student-faculty interactions could also develop as students' college careers progress.

Seniors, on the other hand, (depending on transfer status to SFSU) have two or more years included in the cumulative GPA variable. Because cumulative GPA for seniors includes several more courses from their college career, compared to the freshmen who have only their first fall semester included, it is more difficult to isolate the effects of having participated in service-learning courses within a specific timeframe. Therefore, freshmen and seniors are analyzed separately when looking at the effects on the dependent variable, namely, the cumulative GPA. Furthermore, the ANOVA's that look at freshmen include specific variables that are unique to their firstyear experience, like fall-to-fall return and cumulative GPA. Similarly, the statistical models for seniors include variables that consisted of years to degree and graduation. In 
what follows, the section will provide results from various quantitative analysis that represent freshmen and seniors experiences in service-learning that speak to the central research question in this quantitative section.

Freshmen Cumulative GPA. A one-way ANOVA was conducted to evaluate the relationship between freshmen cumulative GPA and the interaction of first-generation status and service-learning in their first year. The primary independent variables include the four comparison groups: (a) FGCS\&SL, (b) NFGCS\&SL, (c) FGCS\&NSL, and (d) NFGCS\&SL. Overall, results show that differences in the cumulative GPA's across groups is not statistically significantly different. $[F(3,697)=1.961, p=.118]$. Therefore, the null hypothesis was not rejected by this analysis, since there is no statistical difference between the GPAs of students taking service-learning courses and those that did not, and no difference between first-generation and non-first-generation students. In other words, freshmen cumulative GPA was not related to first-generation status or service-learning participation. The means, standard deviations, and the p-value for the groups reported in Table 7.

Table 7. ANOVA - Cumulative GPA by Freshmen

\begin{tabular}{lccccc}
\hline Comparison Groups & $n$ & $\mathrm{M}$ & $S D$ & $\mathrm{~F}$ & $\mathrm{p}$ \\
\hline Freshmen & & & & 1.961 & .118 \\
FGCS \& SL & 261 & 2.99 & .633 & & \\
NFGCS \& SL & 123 & 3.07 & .710 & & \\
FGCS \& NSL & 177 & 3.07 & .648 & & \\
NFGCS \& NSL & 140 & 3.15 & .584 & & \\
\hline
\end{tabular}

$\mathrm{M}=$ Means, $\mathrm{SD}=$ Standard Deviation 
Freshmen Retention. A chi-square analysis was then used to determine the if second-year retention for freshmen was independent of first-generation status and service-learning participation. The analysis included 710 students who met the criteria of be included in one of the four comparison groups (FGCS\&SL, NFGCS\&SL, FGCS\&NSL, and NFGCS\&NSL). Once again, the statistical relationship between these variables was not significant, $X^{2}(3, \mathrm{~N}=710)=4.095, \mathrm{p}=.251$. In other words, this means that the analysis failed to reject the null hypothesis of independence. Table 8 shows the p-value for the chi-square of the comparison groups used in this analyses and it displays the frequencies and percentages of retention for freshmen in the study.

Table 8. Chi-Square Retention Status with Comparison Groups

\begin{tabular}{lccccc}
\hline Academic Variable & $\begin{array}{c}\text { FGCS\&SL } \\
\mathrm{n}(\%)\end{array}$ & $\begin{array}{c}\text { NFGCS\&SL } \\
\mathrm{n}(\%)\end{array}$ & $\begin{array}{c}\text { FGCSL\&NSL } \\
\mathrm{n}(\%)\end{array}$ & $\begin{array}{c}\text { NFGCS\&NSL } \\
\mathrm{n}(\%)\end{array}$ & $\mathrm{p}$ \\
\hline Retention & & & & & .251 \\
$\quad$ Continued & $234(89 \%)$ & $104(84 \%)$ & $155(87 \%)$ & $117(82 \%)$ & \\
Did Not Continue & $30(11 \%)$ & $20(16 \%)$ & $24(13 \%)$ & $26(18 \%)$ & \\
\hline
\end{tabular}

Senior Cumulative GPA. Next, a one-way ANOVA evaluated the relationship that first-generation status and service-learning participation had with senior cumulative GPA. Similarly, as with the freshmen ANOVA analysis, the independent variables included the four comparison groups: (a) FGCS\&SL, (b) NFGCS\&SL, (c) FGCS\&NSL, and (d) NFGCS\&SL. Results for this ANOVA also showed that there was no statistically significant difference in senior cumulative GPA across were nonsignificant effect the four comparison groups $[\mathrm{F}(3,1729)=.865961, \mathrm{p}=.458]$. Once again the analysis failed to reject the null hypothesis of no difference, and it could not 
be determined if first-generation seniors who had taken service-learning coursed performed better academically. The means, standard deviations, and p-value for the groups are reported in Table 9.

Table 9. ANOVA - Cumulative GPA by Seniors

\begin{tabular}{lccccc}
\hline Comparison Groups & $\mathrm{n}$ & $\mathrm{M}$ & $\mathrm{SD}$ & $\mathrm{F}$ & $\mathrm{p}$ \\
\hline Seniors & & & & .865 & .458 \\
FGCS \& SL & 630 & 3.15 & .517 & & \\
NFGCS \& SL & 461 & 3.20 & .526 & & \\
FGCS \& NSL & 332 & 3.16 & .534 & & \\
NFGCS \& SL & 310 & 3.18 & .540 & & \\
\hline
\end{tabular}

$\mathrm{M}=$ Means, $\mathrm{SD}=$ Standard Deviation

Graduation and Senior Years to Degree. The first analysis in this section is a one-way ANOVA that determines if there is a statistically significant difference in the years to degree for seniors based on membership in any of the four comparison groups, FGCS\&SL, NFGCS\&SL, FGCS\&NSL, and NFGCS\&SL. It is important to point out, in what follows, the effects of service-learning on time to degree is only with the firstgeneration college students and not with the non-first-generation college students.

Overall, the ANOVA analysis reveals that there is one statistically significant difference for years to degree for seniors between one of the comparison groups at the 0.10 level of significance $[F(3,1729)=2.219, p=.084]$. The post-hoc comparisons using the Fisher LSD test further specifies that the mean score for FGCS\&SL (M=3.7, $\mathrm{SD}=1.9779, \mathrm{p}=.011$ ) was significantly different from all other groups: NFCS\&SL $(\mathrm{M}=3.8, \mathrm{SD}=2.3994, \mathrm{p}=.260), \mathrm{FGCS} \& N S L(\mathrm{M}=4.1, \mathrm{SD}=3.6646, \mathrm{p}=.132)$, and 
NFGCS\&NSL $(M=3.9, \mathrm{SD}=.471, \mathrm{p}=.227)$. This ANOVA analysis, therefore, reject the null hypotheses of no difference since first-generation seniors who take service-learning courses perform significantly better than their first-generation counterparts that did not take service-learning since they are graduating in an average of 3.7 years compared to an average of 4.1 years, respectively. Additionally, there is a statistically significant difference apparent when also comparing first-generation students to non-firstgeneration counterparts when they both take service-learning, namely, when taking service-learning first-generation participants are graduating in an average of 3.7 years as opposed to an average of 3.9 for non-first-generation participants.

Moreover, when including transfer status, the one-way ANOVA also shows a statistically significant difference on years to degree for seniors among the four comparison groups at the 0.05 level $[F(1186)=3.248, p=.021]$. The post-hoc comparisons using Fisher LSD test further highlights that years to degree was different for all seniors, including those who had transferred to SFSU during their college career as illustrated by the average years to completion. Specifically, for FGCS\&SL (M=3.0, $\mathrm{SD}=1.944, \mathrm{p}=.003)$ was significantly different from NFCS\&SL $(\mathrm{M}=3.1, \mathrm{SD}=2.665, \mathrm{p}=$ $.432)$, FGCS\&NSL $(M=3.7, S D=4.103, p=.030)$ and NFGCS\&NSL $(M=3.4, S D=.471$, $\mathrm{p}=.140$. Whether we are looking at senior years to degree as a the whole, by the comparison groups, or by filtering transfer status, both of the analysis were significant for first-generation college students. In other words, first-generation college students that were taking service-learning were graduating sooner than every other group at a 
significant level. The means, standard deviations, and p-values for the senior years to degree analysis mentioned above are reported in Table 10.

\begin{tabular}{lccccc}
\multicolumn{6}{l}{ Table 10. ANOVA - Years to Degree by Seniors } \\
\hline Comparison Groups & $n$ & M & SD & F & P \\
\hline All Seniors & & & & 2.219 & .084 \\
$\quad$ FGCS \& SL & 634 & 3.65 & 1.977 & & \\
NFGCS \& SL & 497 & 3.82 & 2.399 & & \\
FGCS \& NSL & 309 & 4.10 & 3.664 & & \\
$\quad$ NFGCS \& NSL & 293 & 3.86 & 2.377 & & \\
Transfer Senior & & & & 3.248 & .021 \\
$\quad$ FGCS \& SL & 445 & 3.04 & 1.944 & & \\
NFGCS \& SL & 317 & 3.12 & 2.665 & & \\
FGCS \& NSL & 234 & 3.72 & 4.103 & & \\
NFGCS \& NSL & 194 & 3.39 & 2.618 & & \\
\hline
\end{tabular}

$\mathrm{M}=$ Means, $\mathrm{SD}=$ Standard Deviation

Finally, closely associated with the analysis that examines the years to degree as a dependent variable is the chi-square analysis that uses graduation as a dependent variable. The chi-square analysis evaluated 2,198 students who met the criteria to be included in one of the four comparison groups studied (FGCS\&SL, NFGCS\&SL, FGCS\&NSL, and NFGCS\&NSL). The chi-square test analyzed the relation between having participated in service-learning courses and graduation for senior participants that had graduated by 2017. Results show that graduation is strongly dependent on membership in the four comparison groups, $X^{2}(3)=16.987, p=.001$. However, the analysis was significant for seniors who did not take service-learning (i.e., FGCS\&NSL, NFGCS\&NSL), it fails to reject the null hypothesis for FGCS\&SL since it was not significant for the main study group. It was statistically significant between the two 
groups of students that did not take service-learning, namely, FGCS\&NSL had an $87 \%$ gradaution rate and NFGCS\&NSL had a 77\% graduation rate. In other words, this means that the analysis failed to reject the null hypothesis of independence. Table 11 shows the p-value for the chi-square of the comparison groups used in this analyses and it displays the frequencies and percentages of graduating seniors.

Table 11. Chi-Square Graduation Status with Comparison Groups

\begin{tabular}{lccccc}
\hline Academic Variable & $\begin{array}{c}F G C S \& S L \\
\mathrm{n}(\%)\end{array}$ & $\begin{array}{c}\text { NFGCS\&SL } \\
\mathrm{n}(\%)\end{array}$ & $\begin{array}{c}F G C S L \& N S L \\
\mathrm{n}(\%)\end{array}$ & $\begin{array}{c}\text { NFGCS\&NSL } \\
\mathrm{n}(\%)\end{array}$ & $\mathrm{p}$ \\
\hline Graduation & & & & & .001 \\
$\quad$ Graduation & $634(80 \%)$ & $497(83 \%)$ & $309(74 \%)$ & $293(76 \%)$ & \\
$\quad$ Did not Graduate & $158(20 \%)$ & $102(17 \%)$ & $111(26 \%)$ & $94(24 \%)$ & \\
\hline
\end{tabular}

Summary of Quantitative Findings

Overall, findings illustrate that the first-year freshmen cumulative GPA and senior cumulative GPAs failed to reject the null hypothesis of no difference across comparison groups namely the groups of NFGCS\&SL, FGCS\&NSL, and NFGCS\&SL. Meaning, when analyzing GPAs for first-generation college freshmen and seniors they were not significantly different to their counterparts, both NFGCS\&SL and FGCS\&NSL. Additionally, freshmen retention also proved not to be significant when compared to the primary study group, since FGCSL\&SL freshmen did not have fall-tofall retention that was significantly different. Finally, FGCS\&SL senior graduation also proved to be non-significant since the graduation rates were consistent across the board for all groups with little difference. 
However, there was an exception when analyzing FGCS\&SL seniors and the years to degree dependent variable across all groups, which proved to be statistically significant for the primary group studied compared to the other comparison groups. The years to degree of 3.7 for first-generation seniors who took service-learning (FGCS\&SL) performed significantly better in terms of graduation than first-generation seniors that did not take service-learning (FGCS\&NSL), who took 4.1 years to complete their degree. Therefore, of the dependent variables analyzed in the study used to measure academic success for both first-generation freshmen and seniors. Namely, GPA, retention, and graduation, only years to degree for first-generation seniors proved to be significant for the quantitative portion of the mixed-method analysis.

\section{Qualitative Analysis}

\section{Research Question \#2.}

The second section of this chapter addresses the following research question: how do first-generation students perceive their service-learning experiences on their academic success? This section presents key findings organized as four significant themes resulting from in-depth interviews with participants at SFSU. Interview topics include descriptions of service-learning courses that FGCS\&SL and NFGCS\&SL were currently enrolled in or had completed in the past, namely, the participants' opinions on the differences in learning with and without experiential learning; participants' class reflections; how participants perceived the quality of interactions with peers, faculty, 
and community partners; and participants' personal persistence and graduation narratives.

\section{Qualitative Results}

This section divides the qualitative results into two parts. The first part provides a broad overview of the findings from the interviews and the second part of this section organizes major findings into various themes. Furthermore, the first part of this section provides the overall frequencies for responses given by the two groups that had taken service-learning courses (i.e., FGCS\&SL and NFGCS\&SL). Then, the second part of this section explains the major themes as subsections with corresponding quotes and analysis. Finally, the third part of this section provides an overall summary and concludes the qualitative part of the study.

Throughout these three sections, the narratives of the third group in this section, the first-generation participants that did not take service-learning (i.e., FGCS\&NSL), will be woven into the service-learning analysis since they provide the essential context of first-generation students that did not receive the pedagogical intervention treatment being studied (i.e., service-learning). Table 12 below provides the interview questions and response frequencies for each of the major themes related to participants' perceptions on the effects of service-learning on their academic success, and they are further discussed in the following sections. 
Table 12. Interview Responses by First-Generation Student taking Service-Learning

\begin{tabular}{lll}
\hline Interview Questions & FGCS\&SL & NFGCS\&SL \\
\hline $\begin{array}{ll}\text { Did the service-learning class help you; } \\
\text { Learn? }\end{array}$ & Yes $(9 / 10)$ & Yes $(4 / 5)$ \\
Learn differently? & Yes $(9 / 10)$ & Yes $(4 / 5)$ \\
Graduate from college? & Yes $(8 / 10)$ & Yes $(3 / 5)$ \\
Prepare for the workforce? & Yes $(9 / 10)$ & Yes $(5 / 5)$ \\
Stay in college? & Yes $(9 / 10)$ & Yes $(4 / 5)$ \\
Be a better student? & Yes $(6 / 10)$ & Yes $(3 / 5)$ \\
Interact with peers differently? & Yes $(10 / 10)$ & Yes $(5 / 5)$ \\
Interact with faculty differently? & Yes $(9 / 10)$ & Yes $(5 / 5)$ \\
Interact with the community differently? & Yes $(10 / 10)$ & Yes $(5 / 5)$ \\
Did you have concerns about the SL Class? & Yes $(10 / 10)$ & Yes $(5 / 5)$ \\
Did the SL class influence your goals (short/long term)? & Yes (7/10) & Yes $(4 / 5)$ \\
On a scale from 1-5, how valuable was the SL class? & $4 / 5(7 / 10)$ & $4 / 5(4 / 5)$ \\
Do you recommend students like yourself take a SL class? Yes $(10 / 10)$ & Yes $(5 / 5)$ \\
\hline & & \\
\hline
\end{tabular}

When asked, "Did you have any concerns about the service-learning course," all the 'participants in groups FGCS\&SL and NFGCS\&SL (the two groups that were enrolled in service-learning courses), responded that they had some significant concerns before taking the course. The concerns mainly revolved around "time" and "scheduling," meaning they were concerned that including a community-based project would require twice the amount of time and twice the amount of work when compared to a regular course. 
The interview findings show that the lack of awareness of how service-learning courses differed from traditional courses prevented several participants from enrolling. Additionally, more broadly, all participants interviewed consistently misunderstood service-learning courses as being categorically distinct from traditional university courses. Participants did not seem to understand how service-learning courses fit into their required general education or major requirements. Instead of viewing servicelearning courses as traditional courses with specific pedagogical practices that make the course engaging, participants would interpret the units as separate from their college track as if it was an exclusive elective class.

However, all the participant's that enrolled in service-learning courses gained an appreciation for the distinct pedagogical tenets of the course once they implemented the practices at their sites. Furthermore, these participants also expressed an appreciation for how the pedagogy contribute to their academic scholarship, especially within their professional life. The initial concerns regarding additional outside class-time became less of an issue for participants once they understood the social context of their academic work within their own personal and professional development.

Furthermore, $80 \%-90 \%$ of participants reported that service-learning courses had helped them learn in different ways compared to traditional courses. This finding was especially true for FGCS\&SL and NFCS\&SL. Additionally, both FGCS\&SL and NFCS\&SL understood that the experiential components of service-learning courses fundamentally altered the nature and content of the course. 
For instance, freshmen participants, in particular, shared several experiences where they were able to apply knowledge gained in a college course to real-world settings for the first time. They were able to get a glimpse of themselves as a future professional in the field. On the other hand, senior participants were already well aware of needing service-learning type courses to gain the experience and skills necessary to enter a professional setting after graduation. Therefore, even though freshmen and seniors are fundamentally at different points in their college careers, both freshmen and seniors had formative learning experiences. Furthermore, freshmen and seniors report that they were both able to "learn" or "learn differently" in service-learning courses as opposed to traditional courses because the course content was applied to a real-world context. Moreover, service-learning courses allowed participants to feel a sense of ownership and greater comprehension of course content through this experiential process.

Furthermore, $80 \%$ of FGCS\&SL participants and $60 \%$ of NFGCS\&SL participants felt that service-learning courses had helped them "graduate from college." However, freshmen found it more difficult to see exactly how the service-learning experience could help them graduate since freshmen were not able to directly correlate the experience with graduation requirements. Rather, freshmen would admit that the service-learning experience was one of the most formative in their college careers thus far. Seniors, on the other hand, at first would not directly attribute any connection between having taken service-learning courses and graduation. For example, several 
would say that "they were going to graduate anyways regardless of the class." However, they would eventually admit that the class did prepare them for the workforce since to them graduation and career readiness were two separate things.

Additional findings also show that $90 \%$ of FGCS\&SL participants and $100 \%$ of NFGCS\&SL participants, regardless of class standing, felt that service-learning had prepared them for the workforce. Workforce development was an underlying theme that cut across all the qualitative responses provided by the students since they were able to see first hand how their schooling applied (or didn't) within a social context. It is important to note that almost all participants understood that real-world experiences were necessary for their future professions, but it was only through the experiential component of the service-learning course that they were able to apply and practice concepts in real time. Even though there were mixed findings on how participants saw service learning as helping them graduate as mentioned above, participants overall all understood how the difference of pedagogy in service-learning courses could directly contribute to their professional preparation during and beyond their college careers. All freshmen and senior participants were always considering their college education in relation to future employment prospects. Therefore, this awareness of service-learning courses providing necessary experience and skills was consistent with both freshmen and senior participants.

For example, one participant who was placed in city hall commented on how immediately they were able to understand how their college education in political 
science was the foundation for understanding policy implementation. This participant stated,

The traditional classroom lectured courses give you the knowledge that you need to take into the professional world, but you don't get any of that professional experience. So like it's all cool that I know about like federalism and how government works but I've never been in a place where I actually see it happen or take part in...so that's why I wanted to do a service-learning course... to get that outside experience" (FGCS\&SL).

Therefore, it was these contextualized components in their education coming together that participants, regardless of there classification, intuitively understood that they were acquiring a unique understanding of policy and laws, beyond theory, which contributed to their future employment preparation.

Furthermore, $90 \%$ of FGCS\&SL and $80 \%$ of NFGCS\&SL participants agreed that service-learning courses had helped them stay in college. However, the participants agreed service-learning help them stay in college but not for the traditional reasons such as tutoring or advising, which is what students usually associate with student support services. Participants reported that the social context of their academic work gave their academic experiences meaning, and many times provided a new perspective on their college careers and their roles within it. Moreover, first-generation freshmen, who agreed that service-learning courses had helped them stay in college, reported that these courses motivated them to stay in college because they felt like "role models" in the 
community as representatives of SFSU and because they were able to get a glimpse of the roles they would be performing as future professionals. Also, many first-generation students of color were very concerned about how their college education could contribute back to their community once they graduated. Even though participants claimed that service-learning courses had helped them stay in college, several were not able to make explicit connections on how service-learning is an resources to stay enrolled in college. Overall, participants were more likely to point to traditional student support services such as tutoring or academic advising as serving the reason for their continued enrollment.

Moreover, $40 \%$ of the participants that did not feel that service-learning courses had "helped them be a better student," reported this because the participants did not understand how these courses directly related to their grades. Furthermore, these participants, according to their narratives, also did not see how it was relevant to their graduation requirements. Students associated the concept of a "better student" to traditional academic indicators that directly contribute to grades, test scores, or graduation requirements. Nevertheless, despite the responses, these participants did acknowledge the benefits of personal and professional growth in areas they did not connect to academic outcomes.

The next set of questions asked participants to comment on the quality of interactions they had with critical members of the on and off-campus community. The majority of the participants agreed that service-learning courses had "helped them 
interact better with peers, faculty, and community partners." It is important to note that all of the participants (except one) stated that they displayed prosocial academic behaviors when interacting with peers, faculty, and community partners for their service-learning course.

Overall, the service-learning course allowed for more open communication due to the social context of the class that required constant feedback between the various constituents involved. The social contexts outside of the class also provided meaningful interactions that directly contributed to the course content by way of social reflections and collaborations. Additionally, respondents reported that their interactions in the service-learning course influenced their interactions with students and faculty in other courses. Moreover, all participants, especially freshmen, firmly believed that their interactions in other courses had improved because the communication had helped dispelled many negative preconceptions of the faculty. One FGCS\&SL student stated, I remember growing up and seeing teachers just as an authority... They were just someone that told you not to do something, and you would go 'here is the stuff you assigned.'

Most importantly, the service-learning courses changed the participants' mindset in this regard because they understood that these courses were giving them a role as SFSU representatives in the community and were exposing them as future professionals. Moreover, the faculty, as practitioners, were professionals in the field that could help them in this capacity. 
Additionally, all FGCS\&SL and NFGCS\&SL participants agreed that they would recommend a service-learning course to "students just like themselves." A majority of FGCS\&SL and NFGCS\&SL participants felt that the experience within the service-learning course influenced their "short-term and long-term goals" by helping them visualize their education in this practice. The examples students gave when identifying the goals that were affect by their service-learning experience were (a) their choice of majors and (b) future professional careers. This was especially true for firstgeneration college students who felt that several college experiences were new and allowed them to understand higher education in a practical way, which is not something they could experience through family networks. Furthermore, for 12 out of the 15 participants that took a service-learning course (i.e., FGCS\&SL, NFGCS\&SL), rated on a scale from 1 to 5 , that their overall service-learning experience was a 4 or 5 . The sentiment was that, unlike their other courses, the knowledge they were acquiring in service-learning courses were unique and situated their education within a broader social context.

The second set of interview questions addressed first-generation students that did not take service-learning courses (i.e., FGCS\&NSL), and their perception of best practices at the university was much more varied. Therefore, the "good" or "bad" courses did not have an overarching theme or underlying experience that unified their views like service-learning courses. Instead, the participant's that shared their positive experiences in higher education focused their narratives around a charismatic faculty 
member or lack thereof. However, even when discussing "good" faculty based on the course content, the conversation revolved around how organized the faculty was or how transparent they were about their course content, expectations, and grading system. In other words, the discussion did not focus on anything in particular about the pedagogy in the course but on how personable the instructor teaching the class was. These students were particularly interested in the course when the faculty member would break the monotony of lectures and traditional course activities with hands-on participation or field trips. Additionally, based on participant narratives, perceived "good" instructors or "good" courses meant courses that were taught by faculty members that did not just depend on traditional lectures or lectures guided solely by PowerPoint presentations. Overall, traditional lecturers and lecturers guided by power points were reported as the worst types of class experiences.

Furthermore, first-generation participants felt that there was a clear benefit to experiential learning components, even when it was not a service-learning course. Field trips or activities that provided hands-on experiences were mentioned several times as "good practice by a good teacher," since it allowed students to process the course content less abstractly. It is important to point out that akin to the first-generation students that took service-learning, these non-service-learning students identified "good" content with courses that allowed them to explore how these college concepts were applied. 
For example, an architect major and first-generation student explicitly remembered when the class went to a city project that aligned with their coursework, and as a class, they were able to discuss and apply their knowledge on the subject first hand. The other four non-service-learning students who were in biology and business also echoed the sentiment mentioned above. Additionally, even when the course content did not lend itself to field trips or some field experience, students were appreciative when the instructors took the time to provide some context to abstract concepts and allowed students to process its application with each other. This way of teaching was preferred as opposed to when instructors presented content without any context and required only "memorization." Moreover, even though this case study focused on college courses, similar perceptions for freshmen would also incorporate "good" classes from their high school experiences that had hands-on and field trip components. Finally, unlike the service-learning section, no definitive narrative was given by non-servicelearning participants when asked about improved interactions with peers or faculty despite the fact that they presented these courses as exemplary.

In the second part of this section below, the study will provide a summary of the significant themes that developed during the interviews, which also fall along the lines of the NSSE engagement indicators identified as contributing to student success. In particular, three major NSSE indicators will be addressed as they correspond to the academic success of the students explored for this mixed-method study; (1) 
collaborative learning, (2) student-teacher interaction, and (3) reflective and integrated learning.

\section{Themes and Engagement Indicators}

When considering the themes and engagement indicators, it is important to point out that seniors participants have been at the university for more extended periods of time and under more diverse circumstances. Therefore, these questions, though similar to the freshmen participants, take on a different nature when addressing these themes since they are more advanced in their studies. For example, seniors have a particular interest in placements within their field since this would directly contribute to their immediate professional prospects, whereas freshmen were looking for their first opportunities to engage in the professional field in any capacity, even if it didn't directly contribute to their studies.

Collaborative Learning. According to NSSE, collaborative learning occurs when classmates "engage in class or group projects either by explaining the material to others or by asking questions" (NSSE, 2015). Unlike the results in the quantitative data, which were mixed for academic success, the participants in the qualitative study reported having positive impacts on their academics as it related to their servicelearning experience in the interviews. This is especially true with regards to collaborative learning. However, as the quantitative data and narratives in this case study suggest, many times positive academic sentiments do not translate into increased 
GPA. Therefore, the qualitative portion of the study will provide themes that contribute to academic success according to the student narratives.

A significant theme in academic success for service-learning students was collaborative learning. Collaborative learning is inherent in experiential learning due to the social context in the classroom and the community. Collaborative learning is of particular interest because these prosocial behaviors speak to the ability of the firstgeneration participants to integrate into school and socially persist, despite the traditional academic and social challenges. The theme of collaborative learning attempts to make sense of how often students come together with other students to make sense of class materials, exams, and projects by asking for help from other classmates.

The interview questions connected to the collaborative learning theme asks the students the following questions: (1) "Do you think participating in these servicelearning courses help you learn?" (2) "Do you think any of your service-learning courses helped you learn differently?," (3) "Describe any academic connections you see between the course material in the service-learning course and the work you did in the community?," and (4)"Do you think that participating in service-learning has helped you be a better student?"

When exploring the differences between service-learning courses and the nonservice-learning courses concerning collaborative learning the FGCS\&SL participant started with the differences in the class dynamics: 
Typically, the way I learn in class is by taking notes, but in the [service learning class], I found that talking it out with other students really helps...getting ideas from people that are also doing the same project as you helps...Just for the topic of disciplining you can hear 12 different takes in the class. "This is the best thing, and this is the worst things." In most classes I usually just take notes, but being able to act out situations in class with other students, being able to talk about specific problems...it's more like communal learning... (FGCS\&SL) In the quote above, a significant distinction in social engagement that is found with service-learning experiences is presented, which promote a positive effect on firstgeneration students' interpersonal behaviors inside the classroom. In vocalizing their experience with other students, they understand that they are not alone in these sentiments, that other students have gone through something similar, and that they have devised possible solutions. Another FGCS\&SL student reinforces these collaborative sentiments in the service-learning course when stating:

We [the service learning class] have a lot of discussions, which I feel is really helpful. It allows for reflections...You haven't experienced what that other individual has, but you hear it from [their] perspective and you reflect, "that happened to me too"...because it puts more things into focus, that maybe you weren't paying attention too...We are all sharing these [service learning] experiences, and maybe only few are calling our attention...you might experience all these things, and maybe you only take a few of them into 
account... The act of the discussion helps you reflect on more things than you are aware of. (FGCS\&SL)

In particular, this is especially noticeable when this FGCS\&SL participant highlights the benefits of having "12 different takes," on any given issue, which points to the fact that sharing and listening to their peers and their experiences can greatly benefit the class understanding on the topic. Additionally, the FGCS\&SL student points out that the collaborative style of learning "makes you reflect on more things than you are aware of," because everyone is sharing his or her knowledge on the issues from different positionalities and stages in his or her development. The context of collaborative and situated learning helps students be more forthcoming about their thought process and understanding about class content since they are talking about things happening to them in the field, which is addressed by the class as a whole. The participants also reported being more welcoming of class feedback related to their school work due to its subsequent application in real time.

Furthermore, for the first-generation students that did not take service-learning collaborative learning was also a focal point of their narratives. However, their experiences and narratives were always limited to two important activities (1) field trips or (2) hands-on activities in the classroom. When asked to provide examples of "good" class experiences FGCS\&NSL students provided the following examples:

Anatomy was probably my favorite class here at SF State simply because we had some kind of hands-on experience with the class. We had cadaver labs, we 
had plastic imitations of organs, and a full plastic human body that we got to toy around with things to figure out where everything goes. And I think that is what made the class enjoyable but then a lot more enjoyable than what a lot of people say it is to learn [because of the hands-on component]. Because if someone were to throw you the name of 200 bones it would be really confusing but if you kinda had a visualization of where everything goes, knowing that they are all in different categories, and having someone show you with actual physical things it would be way easier than me just throwing you a list. (FGCS\&NSL)

Another FGCS\&NSL student provided an example that had both of the key experiences, which included a field trip with hands-on activity in the community, which made the experience according to them even more meaningful:

I really liked my design studio class, back in my community college, because it was really hands-on. And some of the projects that we had, the bigger ones, was that we took a tour of the Los Angeles River and we had to build a structure...something having to do with a water catching system. And then a different project was visiting Joshua Tree, we camped there for a weekend, and we had to build a structure to put on top of a mountain. Again, that was very hands-on. You were there, you experienced the actual site to see..."oh, you know this material would work better than this material because you have actually been at the site." Yeah, it was the hands-on. However, most of the other 
[traditional] classes are you know in a classroom, just learn what is on the board, have a test on it. (FGCS\&NSL)

For most first-generation students, regardless of participation in a service-learning course, the context of applying their education in the real world facilitated better collaboration with other students and encouraged them to learn together on their own with their projects. However, this was categorically different from a one-time activity like a field trip or hands-on activity that the third group, the non-service-learning experienced (i.e., FGCS\&NSL), because the experiential component was the underlying theme of the class. In this sense, academic success, as the student narratives suggest, was creating the conditions for the possibility of better authentic academic collaborations with their peers, faculty, and community partners built around a project that provided real-world context. Collaborative learning, in this sense, takes the pedagogical "social-turn" by making the student's interactions participatory and socially engaged.

Finally, the collaborative narrative themes were particularly prominent with the freshmen first-generation participants interviewed for this study since many times they were attempting to navigate higher education successfully and needed the context of their peers as a gauge. As the narrative above suggests, first-generation students are more academically inclined to collaborate in a service-learning course since it is necessitated in the community work itself, as fieldwork. It is central to the class 
experience, reflections, and assignments through the community-based projects, as opposed to field trips or hands-on class activities, which are peripheral in the overall pedagogy of the course. In other words, the experiential component is woven in through the whole class experience as opposed to being constrained within one specific course activity, and the student narratives reflect that sentiment.

Student-Teacher Interaction. This kind of interaction defined as "meaningful engagement with faculty or staff by discussing career plans, school work, and academic performance" inside and outside the classroom (NSSE, 2015). Similar to the students that mentioned collaborative learning above, the students that were interviewed in this study displayed positive regard for the impact on their academics as it related to their relationship with their service-learning faculty, and other key people in their education.

The questions that directly asked students about their academic success related to the student-faculty interaction theme in the interviews are as follows: (1) "Do you think that your experiences in service-learning helped you to interact or think differently with faculty?," (2) "Do you think that your experiences in service-learning helped you to interact or think differently with peers?," and (3) "Do you think that your experiences in service-learning helped you to interact or think differently with the community?" The same questions were given for all three groups to understand the quality of interaction they experienced with key people that would contribute to various aspects of their academic success in the course and college in general. 
Seniors in the interviews at all times had an acute awareness of themselves out in the "real-world" since they were about to leave the institution to start their careers. Therefore, the nature of these conversations for seniors would focus on creating experiential learning opportunities for themselves that would help them formally develop a more professional relationship with faculty (as experts in the field), around careers, and academics. This sentiment was unique from freshmen since there was a sense of urgency and timing associated with seniors due to their future professions. Freshmen narratives, on the other hand, revolved around finding their voice within their newfound role in the institution of higher education and the community, since they were the first in their family to achieve this level of education. Nevertheless, service-learning helped faculty break away from the monotony of classroom only education to focus on the actionable items they would soon face in their service sites for both of these groups of students.

The student narratives in this theme show that, for students, the opportunity to interact with faculty outside the confines of a traditional classroom also enhanced the quality of the learning environment. The faculty member role as the practitioner expert allowed them to lead students to transition into the field in a way that was effective for most students. Many times seniors in the interviews stated that they would search out these experiential learning courses (i.e., internships) that embedded them with professionals and the community. 
For FGCS\&SL seniors, the sentiment was similar whether these courses were mandatory or not because they saw service-learning as directly applied to their transition out of college. Therefore, the senior narratives took on a more serious tone than that of freshmen due to the impending graduation and the recognition that they were building skills that would help them in their careers;

...for [service-learning students] we have [the teacher] to come back to. That is helping us in the classroom. How can I address the situation? ...So sometimes we get asked, what is going on in the classroom? And based off of that, then that determines like the next class. Okay, so we're going to be talking about this, because these are the problems that most of you are dealing with [in the field]... (FGCS\&SL)

This FGCS\&SL student goes on to say that this level of attention that comes with an environment where the people involved care about the outcomes because they have to be applied in a real way. The next FGCS\&SL student expresses the sentiment that both the student and the teacher would be more invested in the work and the outcomes that came from it, compared to traditional courses, because the context would continuously be evaluated and inform the next steps in practice. The FGCS\&SL student quoted here brings up an interesting relationship with the faculty when juxtaposing a graded assessment outside of the classroom, and how that might translate into their practice. Being in an environment where people [faculty] want to help you better yourself is different. In other classrooms you get a book, you read from a test, but you 
don't actually apply those things... You can get a B or a $\mathrm{C}$ in a class, so that means you could have done more work but when you go apply it out in the real world, does it apply at a B or C level? In the service-learning class, the teacher constantly tells me "this can be better...this can be different." (FGCS\&SL) In this comparison, she is alluding to the fact that an adequate education is more than just earning a good grade since the purpose of the practicum is to "be better" at what they are learning to do. The service-learning course is in pursuit of excellent grades, but even more critical is being an effective practitioners in the field. This practicum experience for both faculty and students participating in a service-learning course creates a heightened awareness of the learning since they are always aware that their actions in the classroom will matter that much more when applied. In particular, they are aware that the short-term actions in the class, if situated adequately in practice, can hone their skills for the better and therefore make these courses that much more meaningful.

This change of mentality about faculty and education is a paradigm shift, which goes beyond the traditional academic mentality that is incentivized primarily by tests and grades. One of the FGCS\&SL students that had a more crystallized view on various educational pedagogies presented a more critical view when stating:

In other classes, it's usually like the professor is lecturing and everyone is taking notes. It's from a top-down, like you are getting info and you're spitting it back out in the test. In this [service-learning] class, yeah the teacher will lead the 
class, but it's always an open discussion. It gives me more ideas, let's all talked. I forget what that is called. We talk, we discuss, and it's not like she is giving us information, and we are receiving, we are all sharing knowledge together. I use to be really shy in my other classes to ask for help, even when I was confused I would stay quiet. But now I don't feel stupid asking for help anymore, because everyone there needs help, we are all in similar positions, we all feel frustrated or lost." (FGCS\&SL)

In the quote above and the interview in general, this FGCS\&SL participant perfectly illustrated various themes associated with what makes the service-learning pedagogy unique, both inside and outside the classroom. The FGCS\&SL participant does this from a more critical lens than most students. However, this quote perfectly captures the dynamic between the service-learning and the traditional classroom in general. The interview with this FGCS\&SL participant is even more engaging since they naturally weaved their examples to broader educational themes and theories connected to their view of education in general. It is because this participant has a more critical lens that they are comfortable expressing their reservations when discussing feelings of alienation as a student, similar to other first-generation students who are enduring their academic hardships in silence. Therefore, service-learning, with a more reflective and integrative learning approach, allows the student to speak in an "open discussion," which according to them, has circumvented the "top-down" approach of traditional faculty interactions. 
Finally, for the first-generation students that did not participate in servicelearning (i.e., FGCS\&NSL) and did not experience their student-teacher interaction in an experiential course, many elements about a "good" class given by the student narratives spoke to the core values of an experiential pedagogy:

Our professor was with us with the design process, every step of the way. So it was very one on one, we really got to experience the difference on how the design process changes and you don't get that in other classes. Every project is personal because everyone was working on their own thing. So it was learning through yourself about how you are doing things. You don't get that in average classroom settings...in any other class you just look at your notes, but in a design class, or any hands-on class, you really need to get into it and look at different angles...the way that you think is not linear, it just goes back and forth. I don't want to say it is out of order but you do go back and 'maybe I'll go back and do this or go back and do that.' (FGCS\&NSL)

When the instructor teaching the course can create the conditions to make "every project personal" it allows students to take ownership of their education. You "learn through yourself about how you are doing things," according to this FGCS\&SL student, and it is this introspection inherent in these field components that the students can get a glimpse of the reflective and integrative nature of experiential learning, even if it is not a proper service-learning course. When faculty creates opportunities for field experiences, it can supplement some of the core service-learning components, but 
unless integrated into the core of the course the results will be marginal and limited to that one experience or another.

Furthermore, in-class hands-on activities, without the field experience mentioned above, can also be beneficial but it is even more limited in scope when compared to an integrated service-learning course. One of the FGCS\&NSL stated that if he had the opportunity to create a class for first-generation college students (like himself) that he would do the following:

I would check in with my students, all the time. I would make sure the students are getting assignments done and not doing them the night before. Instead of just throwing an exam at them and hoping that they memorize everything...giving them an opportunity to work in groups, group work would be a big concept that I would practice. I think that is huge. I would do as many activities as I could with my kids. I would try to make the most hands-on experiences for the students with some kind of practice in the field. (FGCS\&NSL)

Faculty who design courses and implement university courses will always be at the center of the student success. However, as both groups of students in the FGCS\&SL and FGCS\&NSL confirmed above, it is when the course content has real-world context, and the students can be involved not just passive recipients of information that the best learning happens. Therefore, creating the conditions for a more integrated classroom that speaks to the student" sensibilities and taps into their strengths is an important 
responsibility for faculty when considering first-generation student college success in higher education.

Reflective and Integrated Learning. Integrating quality student engagement from course material is one of the most challenging things to accomplish with a curriculum; however, it has shown in the interviews that a more integrated and reflective experience for the academic content added significant value to the class. Reflective and integrated learning takes into account "how the student made connections with their prior experience and knowledge" (NSSE, 2105), which is at the core of the service-learning experience. These narratives focus on how the students interpreted their interactions in the service-learning course and how they translated these experiences to improved college experiences that directly contribute to their reflective and integrated learning.

The questions that directly asked participants to reflect on their learning in their college careers are as follows: (1) "What types of reflections did you do in class to help you make connections between the service and learning?," (2) "Do you think any of your service-learning classes helped you learn differently?," (3) "Describe any academic connections you see between the course material in the service-learning class and the work you did in the community?," (4) "Do you think that participating in servicelearning has helped you be a better student?," and (5) "Did your professor give any assignments that helped you reflect on your experiences between what you were learning in class and the real world?" 
Having the opportunity to tap into the students' previous knowledge and use it as strengths is always a positive when thinking about situated learning, such as servicelearning. One FGCS\&SL student put it in the following way:

In the [service learning] class I always think about the ways I can do better...To see their [the kids] progress is really motivating, but hear new ideas in the class [from peers and faculty] it's even more motivating. It makes me feel more creative, I'm getting input from someone that is a professional. So like I don't feel like I'm doing a bad job, if they are telling me 'oh, yeah...you are on the right track" you get it, go ahead and do your own thing with that method.

\section{(FGCS\&SL)}

Class feedback is not something students usually look forward to in traditional courses because faculty mainly focus on the student's grammar, syntax, arguments, grades, or rigor of the writing (i.e., summative assessment). In a service-learning course, feedback has a fundamentally different nature because the community-based project makes the assessment of the class more than just writing, it also has a strong evidence-based component (i.e., formative assessment). Therefore, FGCS\&SL students do not shy away from it, in fact, they look forward to it because they "need to be more creative" with their application. Moreover, the feedback of students work, whether it be from faculty or peers, becomes less of a judgment on their abilities but more of a contribution to their skill development. However, it is the integrated nature of their experiential learning that 
allows for these reflections in writing, group work, and office hours with professors that much more meaningful.

In another part of the interview, another FGCS\&SL student identifies this theme and says the following regarding their experience as an SFSU student reflecting on their development in a service-learning course and their contributions beyond the classroom:

I never expected college to be like that [experiential learning]. I expected college to be a giant auditorium with one professor. We take two quizzes a month, and that's it. In this [service learning] class I feel the professor really cares that we are learning. They care about the way we practice that knowledge, that we do it correctly. There is a lot of care about the progress we make. It's not just like, "here is your info get out there"...are you doing the right thing with that information... What are you doing with that information to make the community around you better? (FGCS\&SL)

Reflective and integrated learning in a service-learning course engenders student engagement in a particular way since they are the central practitioner, as demonstrated in the student narrative above. It also allows them to make mistakes and learn how to be better at what they learn in class by allowing them to scaffold the theory into practice. In contrast to their views of other courses on campus, FGCS\&SL students felt that what made the service-learning course unique was that it helped them visualize their education at SFSU in ways that gave them a sense of confidence. This confidence translated into requests for feedback on their work and looking forward to it since they 
understood why it needed to happen in practice. In this sense, it was not a criticism but advice as a practitioner, and they looked forward to it. In fact, they requested it. Therefore, the service-learning classroom supports students' reflective and integration in their college learning, which translates to persistence in their educational goals both inside and outside the class.

According to this FGCS\&SL narrative, it is how service-learning students all "care about the way [they] practice the knowledge," which leads the students to "feel more creative" about their academic, educational, and professional development. Additionally, the "care" and "creativity" expressed in the interviews seems to allow the student to feel a sense of ownership in their education and class content as it informed their practice in the field as SF State representatives. All of which intentionally integrates their experiences into various aspects of their education and motivated them to think outside the context of the class and beyond their immediate assignment and grade. Most importantly, it empowered them to make connections with their prior experience and knowledge that they bring with them.

Returning to FGCS\&NSL students interviewed, the reflective and integrated learning for them came in many forms even when their class was not a service-learning course. The sense of purpose in their site placements, having a space to practice their college education, knowing their college context in practice, contributing to the community, preparing to be better future professionals, and most importantly being educated by a practitioner in the field were present in the narratives. Nevertheless, 
despite not being service-learning students, their narratives on good classes still parallelled the philosophy of an experiential learning pedagogy when stating:

The first big trip we had was the LA river trip, and it was extremely eye-opening because I never knew that there was actually water in the LA river. A lot of people just think it is a draining system....but it has a lot of beautiful spots to it. It makes you connect a little more, and it helped me connect more with what architecture is and what urban planning is too... it's not only about building a structure, but it's about what is around it, the people...and making that connection to the community. After that [class] experience, I wanted to make design changes and not just be a drafter...the person that just draws the blueprints." (FGCS\&NSL)

This dynamic of reflective and integrated learning within an experiential environment, for both student and teacher, brings the first two themes of collaborative learning and the quality of student-teacher interactions center stage since as future professional they are attempting to improve their skills. However, this was not always the sentiment for students that did not take service-learning since their perceptions of the contributions of good classes were not under a unifying pedagogical theme. However, even when pointing out activities like field trips and hands-on class experiences, which were best practices according to their perceptions of "good classes," they still provided important context for their own needs as students. 


\section{Summary of Qualitative Findings}

The qualitative analysis addressed the research question: how do first-generation students perceive the benefits of service-learning experiences on their academic success? As mentioned above, the interview questions addressed the following major topics; the difference in learning with experiential learning; class reflections; the quality of interactions with peers, faculty, and community partners; professional development and career readiness; and persistence and graduation information. Additionally, this qualitative study focuses on three specific themes that contributed to their academic success as students: collaborative learning, student-teacher interaction, and reflective and integrated learning.

Overall the section on collaborative learning explored how students came together as peers to engage in the class and community-based project, either by engaging with the course materials or how they came together to put into practice what they were learning at school. Student-teacher interaction, on the other hand, highlighted how service-learning courses created the conditions for meaningful engagement between the teacher and students regarding their personal, professional, and academic development during these community-based projects. Finally, reflective and integrated learning took into account how service-learning students made connections with their prior experiences and knowledge to enhance their understanding of class content and future professions. 


\section{Overall Discussion}

The quantitative analysis from the dataset addressed the research question: do first-generation students who have taken courses with service-learning components perform better academically than those who have not taken service-learning? The GPA analysis regarding the first research question failed to reject the null hypothesis for all freshmen and senior cases when looking at them within their general comparison groups. In other words, first-generation college freshmen and seniors did not have better cumulative GPAs when compared to their counterparts. Furthermore, the results of the analysis on freshmen retention and senior graduation also was not significant and failed to reject the null hypothesis. Therefore, the two analysis for freshmen and two out of the three analysis for seniors did not prove to be significant.

There was one exception in the quantitative analysis when looking at senior years to degree completion, which proved to be statistically significant. In other words, first-generation seniors taking service-learning performed better than non-firstgeneration seniors taking service-learning, first-generation seniors that did not take service-learning, and non-first-generation seniors that did not take service-learning. However, this exception did not translate to senior graduation, since first-generation senior graduation was not significant even though seniors years to degree was.

However, unlike the quantitative portion of the study, the qualitative data presents a more nuanced association to student academic success beyond GPA, retention, and graduation, which at times can be binary in its results (i.e., significant vs. 
non-significant). Though service-learning allows for some unique ways of teaching a class and interacting with the students that came across the qualitative interviews, it did not directly translate to the academic success measures used in the quantitative section. Due to the fundamental difference between qualitative and quantitative research, it might be difficult to reconcile the modest findings in the quantitative section when compared to the more robust findings in the qualitative section, especially since this study starts with the NSSE secondary data. A different quantitative assessment of outcomes specially designed for the service-learning courses being used for the qualitative interviews would be more beneficial to reconcile this difference. Nevertheless, in the qualitative section, the student quotes were presented for each theme that emphasized academic success due to their formative experiences in servicelearning, which many times were complimentary when juxtaposed to the quantitative data. 
Chapter 5: Discussion and Implications

\section{Overview}

This mix-methods case study explored how service-learning components improve student's academic success at SFSU. Specifically, this case study emphasized the first-generation college student participation within experiential learning in higher education. Service-learning is an experience-centered pedagogy that allows students to situate their strengths and experiences at the forefront of their education. Therefore, this case study rejects the deficit model of college student success, which focuses on student weaknesses rather than student strengths. Instead, this case study identifies ways to situate service-learning in higher education and explores various academic interventions and pedagogies based on student-centered needs, which challenges traditional classroom settings. Student GPA, retention, years to degree, and graduation were the principal dependent variables used in the quantitative portion of this study to predict academic success.

This chapter is divided into three sections. The first section summarizes the quantitative findings in regards to first-generation student outcomes across specific institutional indicators such as cumulative grades, retention, and graduation. The second section of this chapter summarizes critical qualitative findings regarding how collaboration, academic relationships, and immersive pedagogical practices in teaching and learning contributed to the academic success of first-generation college students. Additionally, this second section focuses on how first-generation students perceive their 
service-learning experiences personally and professionally, which was a major theme in the student narratives. The third section of this chapter provides an overall synthesis of the qualitative and quantitative findings and provides suggestions for future research and practice.

\section{Interpretation of Findings}

\section{Quantitative Analysis.}

This section discusses the five variables used to measure academic success for students participating in service-learning courses in the quantitative analysis. Recall that the guiding research question for the quantitative analysis asked whether firstgeneration students spanning multiple class standings, who have taken courses with service-learning components, perform better academically than those who have not taken courses with service-learning components.

Cumulative GPA. The first dependent variable that measured academic success was freshmen cumulative GPA. The average freshmen cumulative GPA in the sample was well above average (3.0). However, the cumulative GPAs for the four comparison groups (NFGS\&SL, FGCS\&NSL, and NFGCS\&NSL) were not statistically significantly different $(\mathrm{p}=.118)$. Meaning, there was no statistical difference in the cumulative GPAs regardless of a participant's comparison group (based on generational status and service learning participation). However, the relatively high mean cumulative GPAs for all of the comparison groups suggests that it might be attributed to other 
factors besides the combination of first-generation status and service-learning participation.

Additionally, there was no statistically significant difference in cumulative GPA for seniors by comparison group. Overall, the lack of statistically significant difference in cumulative GPAs, for both freshmen and seniors in this study is consistent with the literature on service-learning and academic outcomes presented in chapter 2 . The literature reports that participation in service-learning courses produced positive academic engagement, but did not find a significant difference on test scores, class grades, and overall GPA (Strage, 2000, Leimer, et al., 2009, Johnson \& Stage, 2018). However, unlike previous research findings, which only focus on servicelearning versus non-service-learning participation comparisons, this study took into consideration first-generation status and therefore expanded the areas of focus that previous research does not address with this population of students.

Furthermore, even though grades are a common and vital marker for student success within higher education, grades and test scores are not always the most comprehensive measurement of student success. This is especially the case for nontraditional students. Non-traditional students are typically older, attend college parttime, live off campus, and have major work or family responsibilities. Even though there is divergent evidence on service-learning effects on GPA and tests, the majority of research highlights promising strategies for students through various practices in service-learning participation that can lead to better academic engagement. For 
example, non-traditional college students in their first year often experience academic marginalization and isolation, which affect their levels of college integration and overall engagement (Engle, 2007). Therefore, the literature on academic integration and service-learning participation suggests a potential to increase overall academic behavior for students in higher education. Moreover, establishing a sense of belonging and purpose may be a more useful gauge of persistence and overall academic success, especially for alienated first-generation students in their first year (Chen, 2005).

If first-generation college freshmen and seniors are achieving a "B" average while enrolled in service-learning courses, which is also what the other comparison groups are averaging, then the statistically significant difference in GPA may not be the variable that distinguishes their academic success without looking at other factors like persistence. The first-generation students that took service-learning in this sample proved to be performing above average based on descriptive statistics. Cumulative GPA is only one academic indicator of many that can shed some light on student success. Moreover, multiple aspects of the first-generation college experience, both qualitatively and quantitatively, need to be explored.

Retention. The second dependent variable analyzed was freshmen's fall-to-fall retention for their first year of college. Freshmen retention was not statistically significantly dependent on membership in any of the four comparison groups.

Even though the analysis was not statistically significant, descriptive statistics show that FGCS\&SL did have the highest retention rate (89\%) compared to all other 
groups. In fact, compared to the broader university, FGCS\&SL participants in this study eclipsed the retention rates of the university's 2017 first-year first-generation freshmen, which was at $79.5 \%$, a $9.5 \%$ difference when compared with these university-wide numbers (AIR, 2018). High retention rates for FGCS\&SL is consistent with the other research findings that show high retention rates for service-learning participants (Bringle \& Hatcher, 2010). Akin to the Cooperative Institutional Research study (Keup, 2006) mentioned in chapter 2 , which explores the relationship between 20,000 student retention in three different types of curricular interventions for first-time, first-year students, namely in service-learning, first-year seminars, and learning communities. The study found that service-learning presented the highest gains in percentage points among the three curricular interventions.

Student retention varies from group to group since students with specific characteristics benefit from different types of activities and in different types of settings, this is especially the case with non-traditional students. Therefore, the variation of meaningful engagement into traditional academic practices has been increasing over time, and the literature on effective educational practices reflects that direction in service-learning.

Graduation and Years to Degree. The variable that measured senior academic success was graduation status. In this case, graduation status was statistically significant dependent on membership in the comparison group, FGCS\&NSL $(p=.001)$. Though the primary study group FGCS\&SL graduated at a respectable rate of $80 \%$, the 
highest graduation rate among all the groups belonged to FGCS\&NSL, which had an $87 \%$ graduation rate. The other two groups, which happened to be the non-firstgeneration students, came in at a graduation rate of $83 \%$ for NFGCS\&SL and $77 \%$ for NFGCS\&NSL.

For some institutional context, the 2016 SFSU Data Book, which has data for the 2011 cohort, states that the graduation rate for first-generation students is $22.2 \%$ when graduating in 4 years and $53.6 \%$ when graduating within a six-year period (AIR, 2018). That means the FGCS\&SL in this study are graduating at a rate of $29.4 \%$ higher than the general first-generation population at SFSU. As mentioned before, though not significant within the comparison groups in the study since all the comparison groups were graduating at around $80 \%$, the FGCS\&SL sample results, when compared to the general institutional data for graduation, is at a significantly higher level.

The third, and final, dependent variable that measured senior academic success was years to degree completion. Unlike the other four dependent variables analyzed above, years to degree was the only academic success measurement for FGCS\&SL that proved to be significantly different. The years to degree variable is a quintessential variable for academic success for both freshmen and seniors since this timeframe spans from their first year on campus and brings a unifying framework to the previous variables analyzed in this case study. In what follows, the study will discuss the years to degree completion for all seniors in the sample. Furthermore, the study also provides 
the analysis for years to degree completion for transfer seniors, in particular, since it provides additional insight to the academic indicator for this specific group of students.

The years to degree completion for seniors in the primary comparison group was not only statistically significant for all FGCS\&SL seniors at a 0.1 level $(\mathrm{p}=.084)$, it was also statistically significant for the FGCS\&SL senior transfers at a 0.5 level $(p=$ .031). In other words, the FGCS\&SL seniors consistently graduated sooner than their counterparts from all the comparison groups. In particular, when focusing on the two first-generation senior groups in the study, namely FGCS\&SL graduated in 3.7 years and the FGCSL\&NSL graduated in 4.1 years (a 0.4 difference), which means that the first-generation seniors that took service-learning courses graduated almost one whole semester before the first-generation college students that did not take servicelearning. Likewise, when looking at these same two groups when disaggregating the data for transfer students, the significance becomes even more pronounced. When looking at just transfer data, the FGCS\&SL senior transfer group graduated even sooner. The mean years for transfers seniors coming in at 3.04 for FGCS\&SL and 3.72 for FGCS\&NSL with a p-value of .003 , respectively, with a mean difference in years of .068 .

Overall, these quantitative results directly address SFSU university-wide student success and graduation initiative goals, which aims to graduate $15.4 \%$ more students to reach its six-year graduation goal of $69 \%$ by 2025 ("Student Success," 2017). 
Specifically, it will contribute to closing the "Underrepresented Minority Gap" that, as of 2017 , is at $9.7 \%$ when compared to the general student population, an increase from $8.5 \%$ in 2016 ("Student Success," 2017). Furthermore, these service-learning results, as stated above, can also benefit transfer student four-year graduation initiatives where it is most needed, with first-generation student populations. The current transfer four-year graduation rate for all students is $75.8 \%$, and the goal for 2025 is $86 \%$, which presents a difference of 10.2\% ("Student Success," 2017). Increased graduation rates for the nontraditional student populations, which currently have the lowest graduation rates across various student communities, can counter the high levels of attrition for these students. Therefore, focusing on first-generation graduation rates and years to degree completion through service-learning participation can improve the university's chances of reaching these goals by 2025 .

Qualitative Analysis

This second section discusses the three major themes of the qualitative analysis that highlights the second research question of this study: how do first-generation students perceive their service-learning experiences on their academic success? The qualitative summary of this mixed method study looks explicitly at several core engagement indicators for student success at SFSU, namely collaborative learning, student-teacher interaction, and reflective and integrated learning. Throughout the participant interviews, the themes of integrated real-world experience and interactions with peers and teachers outside of the classroom come across these core engagement 
indicators within the students own words. In the section below, the study goes into more detail regarding the themes stated above.

Collaborative Learning. Collaboration for service-learning participants includes engaging in class and group projects that encouraged them to vocalize their needs as a student practitioner in the field. Additionally, as stewards of their communitybased projects, the service-learning participants oversaw the effectiveness of their work, either by explaining the material to other students or by asking questions to other students about the class content to complete the project at hand. These narrative findings show high-levels of collaboration, engagement, and communication among key stakeholders in the campus community and abroad, and the student narratives support this outcome. Community-based project substantially underpinned the course content especially for FGCS\&SL participants, the practice drove the assignments, reflections, discussions, and class interactions in such a way that the students invested in their work and that of others.

Overall, all participants expressed a desire for more engaged educational practices in the classroom that are different from a traditionai course based on lectures, which was described by the students many times as monotonous and not engaging. Additionally, participants state that their service-learning experiences contributed to their overall success in their personal, professional, and academic development due to the many levels and environments of the collaboration in the course. This added 
community collaboration allowed them to include an entirely new element by addressing community partners that amplified class cooperation.

For participants, adding these community cooperation components fundamentally changed the nature of the class because the community-based project generated a sense of teamwork beyond their peers, which included community partners and instructors. The service-learning participant, as a practitioner, was confronted with various situations in the field that necessitated teamwork. Therefore, this teamwork required the service-learning student to collaborate with their peers, teachers, and community partners to address a social problem as part of their class assignment. It also pushed them to engage their course content for possible solutions with realworld collaborative applications, which they do not identify in their reflection of traditional course expectations. Most importantly, the service-learning courses had a strong professional development dimension that students knew they had to put into practice what they were learning. When juxtaposing the participant's service-learning course with their traditional courses, participants stated that everything in a traditional course felt hypothetical and only applicable to future scenarios.

Finally, according to the participants, the collaborative community context of the course application also positively affected the instructor who were more inclined to make meaningful assignments as an integrated part of their course structure. Furthermore, a certain level of customization occurred with course content as participants confronted a real community issue. Students, according to the narratives, 
perceived their instructors to be more invested in the course and their learning because of the application of the course content in the community.

In concordance with Yeh (2010), the collaborative nature of service-learning with non-traditional students created a sense of resilience in the students with their peers. Resilience is of particular interest because it speaks to the ability of the student to immerse themselves in their coursework and academically succeed despite the academic challenges. Yeh states that it is this inherent collaborative nature of "civic learning" that enables the student to cultivate a meaningful engagement with the course content, instructors, community partners, and peers, bolstering their academic and social competence. Moreover, the collaborative learning conveyed a self-sufficiency of the students that comes with meaningful integration and a sense of ownership with the community-based research that cut across person, professional, and academic development.

Collaborative learning was a core component of the service-learning course because the students needed to work with others to accomplish the task at hand, either individually with their sites or as a group for the community-based projects they were working on in the course. However, it is important to point out that the conception of collaborative learning in a service-learning course is fundamentally different from collaboration in non-service-learning courses because (a) it pushes the boundaries of the course content to include the community writ large and (b) it raises the stakes of the course assignments for both students and instructors due to its 
application. At best, traditional college collaborations within a course occur within the confines of the classroom and are limited to particular tasks like presentations, papers, group projects, and in-class discussions, which many times are hypothetical and abstract content. The collaborative learning component within a service-learning course, on the other hand, has the in-class collaboration elements of a traditional course, but it then enhances these tasks by adding the community-based project, which raises the collaborative stakes on several levels.

Student-Teacher Interaction. Meaningful engagement with the instructor is an essential component of service-learning participation. Meaningful engagement anchors the community-based projects because instructors are experts in these specific related fields. Additionally, service-learning placements are set up as the conditions for the instructors and students to discuss career plans, assignments, and academic performance beyond the classroom in a more meaningful way, which makes course content engaging to the students. More importantly, it allows the student-teacher interactions in the course to be able to apply the learning outcomes to personal and professional developments related to the practice.

The Mckay and Estrella study (2008) explicitly looks at the juncture of firstgeneration college students and service-learning in relation to the quality of interactions in these courses for both students and instructors. In particular, the study demonstrates that situating community-based research for students and instructors to interact outside the course developed a higher quality of interaction with the instructors and peers inside 
the course. These findings support that the instructor can be strategic with course-based interventions in guidance, support, and self-development that first-generation college students need with networks that already exist in the classroom and the community. However, the primary resource in these courses are the teachers because they are the professionals who guide the connection between their coursework, the students, and the practice. Finally, many times the instructors are the first professionals that many firstgeneration students work with in a meaningful way, which might not be an experience they have at home. It is important to point out that part of the challenge of being a firstgeneration student is not having a parent with a college degree, but it also means not having a parent with a profession associated with that level of education and the access that comes with combining both of these elements.

In an institution of higher education that continuously assess student success with quizzes, exams, grades, and tests (i.e. summative assessments), service-learning courses are a change of pace for first-generation students and provide a different measure of academic success, which is based on their experience (i.e. formative assessments). Instructors teaching the courses at the university are the main point of contact for the students throughout their college careers, thus teaching courses like service-learning would allow for pedagogies in the classroom that lend themselves to meaningful interactions between teacher, students, and their environment. The shift in student-teacher interactions can be helpful for first-generation students in their first year when a connection with the instructor and the course content is most critical in 
preventing attrition. Furthermore, a more engaged classroom with experiential learning components can help address disengagement that first-generation college students experience with traditional course structures, which many times leads to isolation, alienation, and high dropout rates.

Reflective and Integrated Learning. Making connections to prior experience and knowledge by re-visiting the student's views in their social context is what makes experiential learning empowering to participants. Situated learning allows students to build on their strengths and build confidence in their education, however, this social turn in education is not new. A service-learning course that welcomes student voices and life experiences as a way to build on their academics empowers the participants. First-generation students are finding their voice within their college education with these practices, and it is an essential first step in taking ownership in their learning. Therefore, the experiential learning model directly counteracts compartmentalized forms of education, which accounts for integrative contexts in and outside of the classroom to accomplish the service-learning components in these communitybased projects.

In agreement with prior research findings, this study finds that service-learning increases students' ability to make integrated connections in and out of the classroom. For example, the integrated nature of service-learning affected first-generation college students' experience of personal efficacy, awareness of the world, personal values, and engagement in class, similar to the seminal work of Eyler and Giles (1999). Therefore, 
service-learning participation is important because it facilitates students' ability to understand complex problems, critical thinking in dealing with complexity, and cognitive development because of the applied experience. Similarly, the students' leadership and career readiness, according to the student narratives, also improved by integrating service-learning in the classroom by facilitating the implementation of the community-based project.

Furthermore, it is important to point out that a robust integration and comprehension of the subject matter had a dramatic effect on the students' selfperception and subsequent academic commitments. The connection with these seminal studies is that service-learning is also found to contain high-quality learning that included course integration through collaboration and experiential learning which positively offset the disadvantages associated with student college disengagement. The FGCS\&SL narratives affirm the literature and suggest that these students can benefit even more from these qualities if exposed to these courses in critical points in their college careers.

Traditional forms of teaching and learning make most first-generation college students feel disengaged and disconnected from their schooling. Traditional educational practices are designed for traditional students to work independently and in seclusion, which is where they excel. Service-learning creates the conditions to puts students in the best possible position to tap into their own experiences and build on these strengths as a collective, where students are there to share their knowledge in an integrative way with 
peers, instructors, and community partners. Most importantly, they can be a support system for each other, which can be an advantage for any student participating in service-learning. However, for these intervention elements to be deployed authentically and strategically for the students that need it the most, colleges and universities need to cultivate a type of learning that allows non-traditional students to integrate their education with the knowledge they already possess.

\section{Summary}

Service-learning, as a high impact practice, can contribute to the university's overall institutional goals. Positioning service-learning as a course-based intervention to counteract attrition of first-generation college students provides a significant opportunity for the school and the service-learning program to collaborate in a more intentional way within an academic setting as demonstrated above.

Additionally, a unifying theme that cuts across all the various academic variables (i.e., GPA, retention, and graduation) and engagement themes (i.e., collaboration, integration, and interactions) explored above is student persistence. Student persistence, unlike retention and graduation, speaks to the student's motivation and feelings of empowerment to continue their learning and engagement despite their academic hardships and institutional challenges. Therefore, it is important to distinguish that persistence refers to a disposition of students to continue where retention is a measurement of a student returning to school. Moreover, contributing to the student's persistence is an academic quality that goes beyond the college parameters, when 
institutional indicators such as retention, GPA, and graduation are not applicable. Therefore, student support services cannot be limited to tutoring or advising, the institution of higher education needs to create the conditions for these students to nurture for themselves.

A second unifying theme that brought together the participant narratives was professional development and career readiness. It is a big part of what student's valued in their education since they were going to be the first ones in their families to achieve the professional careers that required a college degree. They identified it as a primary focus as to what they perceive to be part of their academic success and the ultimate purpose of their studies. In this sense, their persistence was intimately connected to their self-actualization as future professionals, mainly since they would be the first ones in their family to do so.

The findings in the qualitative section above are in agreement with the Bringle and Hatcher study (2010), which points out that infusing service-learning into first-year experiences makes for meaningful course interactions in the college environment that directly contributes to persistence. In the Bringle and Hatcher study, the re-enrollment numbers were due to the student's self-reported results on the "quality of the learning environment" that was due to the "enrollment [in] service-learning," which had a strong correlation in the study. Studies in persistence and retention, as discussed in chapter 2, which review the pedagogical practices that address students in their academic and 
social experiences, have been at the forefront of expanding our understanding of the student's desire to continue their schooling, and it continues with this study.

Finally, it is important to point out that student participants shared that their experience with service-learning participation affected the way they approached their education. According to the student narratives, it was situated learning that allowed them to apply concepts they were learning in school to a real social problem, which was unique from the rest of their college careers. However, even when sharing the positive academic experiences, better grades were never explicitly identified as a factor in the interviews. In part, because freshmen participants were still taking their first servicelearning courses and the final class results were not part of the conversation. Seniors, on the other hand, also never mention grades when asked about their academic success in service-learning courses but instead would emphasize their academic experiences as it related to their site placements. In other words, this means that for students, high grades are not tied to measures of real learning or college success.

\section{Limitations of the Research}

Overall, four limitations to this case study need to be considered. The first limitation is the insufficient SFSU data that is a census of the students and faculty participating in service-learning courses. Overall, this census provides useful descriptive data for 200 courses designated as "service-learning." However, the SFSU data lacks both quantitative and qualitative measures that specifically address issues in student and faculty experiences in service-learning participation. The SFSU data should 
still be considered a work in progress that needs to consider additional measures and data collection procedures to better capture various aspects of service-learning courses and the experiences of students and faculty in these courses. Therefore, due to the lack of variety of measures in the SFSU data, this case study needed to include additional data from NSSE. The measures that NSSE was able to provide that SFSU data did not include reports on service-learning participation by individual students. Even though this case study was able to utilize an additional dataset (NSSE data), there were still several necessary measures needed which prompted the additional need for the qualitative analysis in this case study.

The second limitation in this case study was the lack of traceable documentation of existing service-learning by all participating faculty and departments. The lack of documentation for participating faculty and departments may be due to an absent reporting system from faculty or departments in the service-learning practice even though SFSU is one of eight of the 23 California State University (CSU) campuses that include service-learning and internship hours on student transcripts. Thus, servicelearning placements are not processed at the institutional level, and necessary information such as placement hours are rarely documented. This lack of documentation then makes it very difficult for the university to track or analyze service-learning experiences. Even though strategies are being devised by the university to collect information on the service-learning participants, the additional longitudinal data 
provided by NSSE is the best option to supplement research on service-learning at the SFSU campus given these limitations.

The third limitation that this case study faced is lack of specificity that addressed service-learning participation in the NSSE survey data. Specifically, the student survey that asks participants how many courses in their college careers have been servicelearning. The survey relied heavily on student recollection of their service-learning courses over time. Therefore, these responses were self-reported by the participants who had to recollect how many courses they had taken within their college careers that had a community-based project (i.e., service-learning). This is a limitation because student evaluations can be biased in their self-reporting and the question did not allow to specify exactly how many courses were service-learning. Instead, freshmen and senior participants in the NSSE survey had to confirm how many of their college classes had service-learning components throughout their college career, which ranged from one semester to several years of coursework. The categories provided for this measure of service-learning participation included, "none," "some," "most," or "all of the courses" they took at SFSU. For this case study's analysis, these categories were collapsed into a dichotomous measure of, "yes" or "no" in regards to having participated in servicelearning courses. Specifically, participant responses of "some," "most," and "all" were coded as "yes," and responses of "none" was coded as a "no."

A final limitation to this case study is that service-learning, as a distinct pedagogical practice, is not an academic term that students are familiar with in their 
studies. This is especially the case for freshmen who are still familiarizing themselves with the various components of university academics. The NSSE definition for servicelearning focuses on a community-based project in a course, which in many cases can be vague and can dramatically vary by institution. Thus, even though NSSE proctors surveys at several institutions of higher education across the nation, there are varying service-learning definitions and implementations at each institution. Overall, the definition of "service-learning" as combining a community-based project with a course would be the most intuitive for students self-reports despite its limitations. Currently, there is no way to determine the experiences of students in the classroom from a pedagogical perspective within the quantitative data as this requires access to curriculum and assignments.

It is suggested that future service-learning course surveys not only consider essential descriptive measures of service-learning participation at the university but that they also implement a course evaluation that collects student qualitative narratives on various measures specific to academic success. Having student success indicators from participating students would significantly improve the understanding of service-learning at the university. This study highlights how it would be beneficial also to analyze other measures of academic success such as grades, retention, and graduation for students who take service-learning courses. Because even though it is useful to know the number of service hour's students invested in the community, it is even more important to know 
how service-learning courses or programs explicitly contribute to college success at the university.

Implications for Practice

This section presents the equity implications of service-learning participation and provides recommendations in practice for further consideration. Policies and initiatives at universities should be data-driven. Thus, institutional blinds spots must be monitored and addressed when these educational gaps are creating institutional disparities. If service-learning as an academic practice in Academic Affairs is to be successful, there needs to be a strong case made for its contribution to the student learning outcomes both in terms of summative assessments (i.e., grades, test scores) and formative assessments (i.e., reflections, observation, discussions). Furthermore, there needs to be a robust data collection plan geared towards service-learning program's contribution to persistence, retention, and graduation, and not just its contribution to community engagement and service. Moreover, the service-learning program needs to interrogate the equity gaps within specific groups that are not participating in the "highimpact practice" of service-learning to confirm that it is, in fact, having an impact on the students that need it the most. There is limited data on the effects of service-learning on students at SFSU and no information on the participation of first-generation college students. Therefore, the critical juncture for both the organization and leadership in addressing these concerns is "institutional equity," which can be understood in practical 
terms as an equal representation, equal access, and equal impact of these resources on the various student communities (Finley \& McNair, 2013).

Therefore, increasing awareness about service-learning and student success among the SFSU students, staff, faculty, and administrators should be a primary goal for the University. The key message should be how academic success through servicelearning participation can make a positive difference in student's education by adding real-world experience to their majors, profession, and scholarship (Bringle \& Hatcher, 2010). Service-learning programs can create needed coordination among students, staff, faculty, and administrators by providing data and analytics on the effects of servicelearning for students in general. This is especially the case for student populations that need the added support, like first-generation college students. The use of technology can help facilitate the process and be integrated to address the challenges mentioned above in several ways.

Students. More attention should focus on student needs for skills development during their education that can assist them in their future careers. Current and prospective students ages $18-25$ are the traditional primary target in a university setting. Age-related research shows that one of the major concerns for young adults is jobs and finances regardless of generational status (Eagan et al., 2014). In 2014, the Cooperative Institutional Research Program (CIRP) survey, administered nationally by the Higher Education Research Institute (HERI), shared that students are increasingly placing high premiums on the importance of career readiness while going to college (Eagan et al., 
2014). The incoming freshmen survey cited, "a better job" as one of the most important reasons for getting a college degree. Additionally, this sentiment was expressed by an all-time high of 87.9 percent in 2012 (Eagan et al., 2014). Therefore, an essential aspect of why individuals pursue a college degree is because they seek quality skills that are relevant to their future professions. These professional incentives, which are inherent in service-learning participation, can be harnessed within the course content to invigorate traditional classrooms and student engagement all the while bolstering the student resume.

Furthermore, the opportunities to network are abundant in service-learning courses for students interested in building their personal, academic, and professional development. San Francisco State University (SFSU) already has a network of more than 200 university approved community partnerships with various service, internships, service-learning, and civic engagement opportunities, in both for-profit and non-profit entities. Furthermore, as the premier public university located in an urban location in the Bay Area, experiential opportunities can be of high quality at SFSU if adequately coordinated. San Francisco is an international hub for intellectual, scientific, technological, and cultural activities, which creates the conditions to infuse quality opportunities for SFSU students and faculty. Additionally, the Bay Area is home to various natural habitats and sanctuaries that are run by premier community-based organizations, which can provide the potential for a wide variety of academic and career affiliations. Finally, a diversity of advocacy organizations within the various 
communities provides the possibility for culturally relevant experiences for students to bring into the classroom - all of which is directly relevant to first-generation personal and professional needs.

Additionally, students seek knowledge and experiences that allow for shared opportunities specific to their major, scholarship, and careers (Eagan et al., 2014). However, traditional channels of university communications (i.e., emails, newsletters, and transcripts) are not resources that resonate with students, especially first-generation students. For this young demographic hyper-connectivity through all the major social media outlets are necessary to build critical awareness on any given topic or issue. Online is where students prefer to communicate with their audience and share their purpose and passion. They are the highest users of social media for various aspects of their lives, educationally and professionally.

For example, at SFSU the university has begun to roll out an ePortfolio system that is akin to LinkedIn, but with more social media integration for college students. The social media integration with ePortfolio includes, but is not limited too, Twitter, Facebook, and LinkedIn, with added features of connecting it to a course management system (i.e., iLearn, Blackboard). However, unlike LinkedIn the ePortfolio system allows the student to connect their profile with an SFSU course to be able to document their community-based scholarship. These online platforms create a virtual space where students can submit their formative assessments by reflecting as practitioners in the field. The ePortfolio platform has also been identified as a high-impact practice, and 
when combined with service-learning it can create a professional space where the students' scholarship and experience are legitimized and formally presented (Watson, et al., 2016).

The social functionality just described in the ePortfolio is essential because for first-generation students it amplifies the purpose of the community-based projects and overall engagement in the service-learning course described in this study. The online tool simultaneously provides the networks and visibility necessary to build a professional profile that caters to the student's career needs. The ePortfolio, as a webbased student work portfolio, if adequately integrated into the collaborations, reflections, and quality of interactions that the service-learning is attempting to establish can harness not only the professional dimensions of the service-learning work but also the academic and collaborative dimensions as well. The synergy of the ePortfolio system with service-learning is unique because unlike other courses that use ePortfolio to document their work (i.e., papers and documents), experiential learning allows the students to place their experiences (i.e. audio, pictures, videos) next to their written scholarship through this evidence based-learning approach.

Faculty. The faculty on campus are critical as the personnel that designs and implements service-learning courses to students. At SFSU, in particular, servicelearning has been embraced by faculty and staff at all seven of the University's colleges, with 52 departments offering students 200 service-learning courses (ICCE, 2014). However, despite the general acceptance and support for service-learning, this 
practice has been underutilized by SFSU students and faculty since it is limited to only a handful of committed people within the university. For example, of the 124 classes that were taught as service-learning at SFSU in the spring of 2018 about 79 faculty taught them, and they were teaching multiple sections.

For the faculty to become more involved in service-learning pedagogies, it will take department leadership (in conjunction with administrative initiatives) to incentivize these co-curricular options within the tenure and promotion process. Moreover, there needs to be a study on why faculty participate or do not participate in service-learning. From this research, we could better address faculty needs to create and implement these courses. Finally, lack of knowledge of already existing resources at SFSU to help create or execute a service-learning course is a problem, especially when the perception is that these courses are too much work and overworked faculty who do not see servicelearning courses as worth their time, or impossible to do with current classroom size and without course release.

Service-learning, akin to the philosophy of internships, can prepare students to engage with a diverse set of circumstances and people in applied settings, which can cater to the overall needs of various departments and careers. The breadth and scope of the community opportunities in career readiness in scholarship, community-based research, and job experience within specific majors are already available to pair with a variety of different academic components. However, these experiential applications are 
not well understood by faculty and departments at times, as mentioned in the limitation of the study section.

If adequately situated, service-learning can be infused with a broad range of existing curriculum as a set of pedagogical tools complementary to course scholarship. Therefore, departments should look into service-learning opportunities that already exist to prepare their students beyond the classroom by making these experiences relevant to their coursework and careers. Finally, department leadership, in partnership with the university, should create incentives for faculty to bolster a percentage of their courses, the ones that lend themselves best to this pedagogy, into additional core General Education courses and major requirements to expose students to these skills early in their college careers. Allowing first-year freshmen, for example, to gain some form of experience in the field, in whatever capacity, would make their class experience that much more engaging and directly connect the students' academic development to a broader social context.

Student-centered learning, if it is to generate student engagement and academic success, must combine educational programs, learning experiences, and instructional approaches that address the interests and aspiration of students on their terms, which includes social platforms like ePortfolio. Therefore, faculty can also look to the new university initiative of ePortfolio to complement their disciplinary and course objectives within service-learning. The ePortfolio system will allow everyone from staff, faculty, and administrators to harness the platform to represent their department learning 
outcomes, namely by incorporating the students work portfolio into their course evaluations, reports, and most importantly data collection. The ePortfolio assessment can also provide authentic feedback about the course (both in the form of formative and summative assessments) since the service-learning participants can contextualize their learning outcomes by reflecting on real course examples in the field and in real time.

Furthermore, the ePortfolio platform supports classroom integration that can lend itself to (1) peer review and instructor feedback, (2) assignment submission, and (3) archives of student progress. Again, all of which contribute to the overall communication and visibility of service-learning outcomes at SFSU on a web-based platform, which resonates with a student's personal, professional, and academic success. Most importantly, it directly contributes to the student's career readiness and overall student engagement. Moreover, it would also facilitate faculty to showcase their student disciplinary work to academic communities on campus and off campus, and professional associations nationwide.

Finally, the underutilization of service-learning courses also derives from a cultural resistance in academia that is reluctant to change traditional teaching practices (Butin, 2006). For many faculty members in higher education, service-learning is questioned as a rigorous practice (Butin, 2006). Therefore, it is not favored as a pedagogical tool in the classroom. Part of the challenge is that service-learning in higher education is missing the inertia necessary to combat the reluctance from faculty accustomed to traditional forms of teaching and learning. The lack of awareness is the 
biggest challenge since communicating the relevance of the service-learning pedagogy to the faculty's discipline is a difficult task. However, conveying the message that service-learning as a high-impact practice is a function of students wanting a meaningful education, not necessarily an aversion to rigorous coursework is an essential first step. Herein lies the potential to apply these findings to students in need of genuine experience in the classroom, namely, by finding a sense of purpose and direct application to their education, which can lead to a more natural and authentic academic commitment.

Administrators. The administration core of the university, through the efforts of student success services is key since they provide programming and infrastructure to the university that can influence student and faculty curriculum decisions. For example, SFSU is one of eight universities in the CSU to include service-learning hours on student's official transcripts, which institutionally legitimizes the students' communitybased scholarship for their graduate school application or subsequent professional work. However, transcripts are not documents that are highly visible nor is it something the student can readily share with their peers or potential jobs. Since administrators set the mission and vision of the university and staff operationalized these services to students, they are vital personnel that can help to situate service-learning pedagogy in such a way that can affect university-wide policy through campus initiatives.

However, a practical implementation plan that starts with data collection must be a central part of the overall strategy for all key constituents mentioned above (i.e., 
students, faculty, and administrators). At SFSU, little to no data exists specific to students taking service-learning in general, let alone on the effects on first-generation college students' retention and graduation. The lack and limitations of current data and overall collection strategy are the most concerning implication of practice for the service-learning initiatives at the university. Institutional data is the information that will allow it to make the argument of relevance on campus to the constituents that it is attempting to address with the service-learning programs. Most importantly, student success data will set the tone and academic rigor associated with this practice if adequately coordinated and integrated into co-curricular activities, such as first-year experience programs, among other student success programs.

Innovative instructional support for students, teachers, classrooms, and curriculum that reflect these educational values needs support from leadership that not only appreciates the experiential component of learning but also encourages the reflective and collaborative process within each of the students as an indispensable aspect of social and academic life. Educational leadership within an equity framework starts from the assumption of needing to advocate for student-centered learning in the classroom from an instructional and administrator position (Fullan, 2014, Shields, 2010). Therefore, organization around institutional culture invested in meaningful educational experiences, such as service-learning and ePortfolios, is at the forefront of this leadership approach since it attempts to make experiential learning part of its instructional core. As an educational leader, this puts a high premium on classroom 
innovation and effective institutional strategies, thus searching for a common purpose in the pedagogical core is a significant key to the instructional and institutional goals. However, to set participation goals for students within service-learning is to envision what full representation is in practice, especially for non-traditional students like first-generation college students. The visibility of student success data allows institutional leaders to investigate if students are underserved in this practice at the institution. Then evaluate if the service-learning representation of service-learning students and non-service-learning students is proportional. Furthermore, address whether these proportions are reaching the students that need it the most. These types of benchmarks are useful for leadership across all the major programs on campus since proportional representation and access allows aspects of the institutional goals of the university to be more accessible to staff, faculty, and administrators (Finley $\&$ McNair, 2013). If service-learning is going to contribute to the broader institutional goals of graduation and retention, then it needs to implement a strategic plan that will address the representation concerns and explicitly align its core services to the university strategic plan and graduation initiatives. Therefore, the service-learning program needs to coordinate the leadership necessary to provide students with a more engaging curriculum and bring together the resources to student support services that are looking for alternative practices to traditional course interventions. 
Implications for Future Research

There is much need for additional research to uncover the implications of service-learning on students success and improve the experience of first-generation college students in higher education. Future research needs to focus on two issues: (1) situate robust service-learning initiatives with various division partners that target nontraditional students and (2) have a rigorous collection of student success data on the initiatives. Targeted research on service-learning course-based strategies is of particular interest and can be an advantage for non-traditional students. At a fundamental level future research needs to collect quality descriptive data and have a process to analyze it, not just self-reports, on students taking service-learning and what it means to their academic success.

A big part of the challenge for future research is due to the breadth and scope of how service-learning is operationalized within each university. This case study reviewed the literature on the gamut of research from within different courses, service projects, empirical case studies, meta-analysis, longitudinal studies, and national survey research, which are not all generalizable to all schools. Therefore, future research needs to create and fund service-learning initiatives that apply to the particular institutions to assess the relationship between service-learning participation and first-generation college student success with special consideration to the resources used at the university. 
Finally, these targeted intervention efforts need to be carefully monitored, coordinated, and studied based on existing best practices. Akin to the program like Metro at SFSU, which is a cohort-based learning community that has wrap-around student services based on themes in accordance to the students' career pathways (i.e., health, business, education), a program model with best practices needs to be created to showcase and study. It is precisely for this reason that Metro has been hugely successful at monitoring non-traditional students and their academic success. A service-learning initiative needs to look into ways to create and collect this type of information with the various programs in the division that already are in existence by strategically integrating experiential learning into the equation (i.e., first-year experience programs) and studying it. Successful student success programs have invested in the research behind their interventions, and it has proven to be fruitful for the programs and the way the university situates the data to university-wide retention and graduation goals. Most importantly, the research needs to focus on exploring how educational practices can mitigate institutional inequities for the changing demographics as a means of addressing systematic equity issues with a first-generation college student population.

\section{Final Thoughts}

Service-learning, with proper institutional support, can not only reinvigorate the level of classroom integration across all disciplinary fields but also provide an innovative approach to much-needed retention and graduation strategies complementary to traditional teaching and student success programs. One of the goals of this case study 
is to create a dialogue and make program recommendations for the direction on how service-learning programs can utilize specific practices to address the needs of firstgeneration college students more intentionally. This case study allows for a deeper understanding of how academic commitments to higher education are created and transformed through experiences in service-learning. Deploying service-learning for the explicit purpose of retention and graduation, not just civic engagement, can create the academic shift necessary to address the problem of practice when addressing firstgeneration college students in higher education.

Despite the limitations addressed above, this case study highlights methods in which institutions of higher education can address a systematic equity issue with a firstgeneration college student population. As mentioned before, an "equity-minded" approach locates responsibility for the educational success of the student in institutional practices instead of the student deficits (Finley \& McNair, 2013). Therefore, there are serious equity implications when it comes to the experiences of first-generation college students in higher education. Especially since they have become over-represented within the underserved student groups (Engle, 2007).

Placement within Academic Affairs affords the service-learning program opportunities to strategically plan with the other student support services within the division, which is central to students' academic success (i.e., advising, tutoring). Rethinking service-learning under this division leadership takes an external re-branding and internal strategic planning and collaboration across various departments, programs, 
and faculty leaders on campus to disseminate the message. Using the concept of collective work and becoming the backbone organization for the various division collaborations should be the centerpieces of the strategic plan for the service-learning program. These collective and collaborative associations will need to develop through formal and informal channels since service-learning can be operationalized in various capacities and can be customized according to the needs. However, first, the servicelearning program needs to reinvent itself as a viable academic support program with a strong career readiness component, dispelling the perception that people at the university have of it as mainly a civic engagement experience.

Service-learning has widespread applications in higher education. It pairs well with existing educational models and practices or can be taught as a stand-alone course with interdisciplinary content. For example, service-learning can be incorporated into a first-year experience by helping the student not only get experiential practice in their field of study but also develop a connection with the community they live in, both on and off campus. Student isolation and contextual awareness of the importance and application of their educational studies is at the forefront of many interventions to enhance student persistence and engagement, service-learning can be a leader in these educational practices. Service-learning educational experiences that help students develop a social context to their education (i.e., work readiness, service-projects) can enhance the students' persistence and overall academic success. 
Finally, a paradigm shift in the conversation is necessary to move the focus from what the students lack to how institutions can transform their teaching practices to create the conditions for student-centered learning, which has clear equity implications. The change in conversation from a deficit to equity model is an essential first step in this educational turn. Effective educational practices informed by research and innovative pedagogy are central to the advocacy, practice, and vision of the schools attempting to bring transformative experiences into the classroom. 


\section{References}

About Us. (2017, April). Retrieved from: http://www.sfsu.edu/ icce/

Academic Institutional Research (AIR). Retrieved from (May 2, 2018), http://studentsuccess.sfsu.edu/

Astin, A.W., L.J. Vogelgesang, E.K. Ikeda, and J.A. Yee. 2000. How service learning affects students. Los Angeles, CA: Higher Education Research Institute.

Ayala, C., \& Striplen, A. (2002). A Career Introduction Model for First-Generation College Freshmen Students.

Brookings Institute, (2015, May). “The Stubborn Race and Class Gaps in College Quality." Retrieved from: https://www.brookings.edu/research/thestubborn-race-and-class-gaps-in-college-quality/

Brownell, J. E., \& Swaner, L. E. (2010). Five high-impact practices: Research on learning outcomes, completion, and quality. Association of American Colleges and Universities. Washington, DC.

Butin, D. W. (2006). The limits of service-learning in higher education. The Review of Higher Education,29(4), 473-498.

Campus Compact. (2014). 2014 Service Statistics: Campus Compact Membership Survey Summary Results for All Public Higher Education Institutions. Retrieved from: http://compact.org/initiatives/membership-survey/

Cahalan, M., Perna, L., Yamashita, M., Ruiz, R., \& Franklin, K. (2016). Indicators of Higher Education Equity in the United States: 2016 Historical Trend Report. 
Pell Institute for the Study of Opportunity in Higher Education.

Center for Postsecondary Survey, National Student in Service Engagement:

Engagement Indicators (2016, March). Retrieved from:

http://nsse.indiana.edu/html/engagement indicators.cfm

Chen, X., \& Carroll, C. D. (2005). First-Generation Students in Postsecondary

Education: A Look at Their College Transcripts. Postsecondary Education Descriptive Analysis Report.

Choy, S. Students Whose Parents Did Not Go to College: Postsecondary Access, Persistence, and Attainment. Washington, DC: National Center for Education Statistics. 2001.

Dewey, J. (1938). Experience and education: the Kappa Delta Phi lecture series.

Engle, J. (2007). Postsecondary access and success for first-generation college students. American Academic, 3(1), 25-48.

Eyler, J. and D.E. Giles, Jr. (1999). Where's the learning in service-learning? San Francisco: Jossey-Bass Publishers.

Finley, A., \& McNair, T. (2013). Assessing Underserved Students' Engagement in High-Impact Practices. Association of American Colleges and Universities. Washington, DC.

Fullan, M. (2014). Leading in a Culture of Change: Personal Action Guide and Workbook. John Wiley \& Sons.

Institute for Civic and Community Engagement (2014), The President's Higher 
Education Community Service Honor Roll Application, San Francisco State University, San Francisco, CA.

Jacoby, B. (2014). Service-Learning Essentials: Questions, Answers, and Lessons Learned. John Wiley \& Sons.

Johnson, S. R., \& Stage, F. K. (2018). Academic Engagement and Student Success: Do High-Impact Practices Mean Higher Graduation Rates?. The Journal of Higher Education, 1-29.

Keup, J. R. (2005). The impact of curricular interventions on intended second year reenrollment. Journal of College Student Retention: Research, Theory \& Practice, $7(1), 61-89$.

Kuh, G. D. (2008). High-Impact Educational Practices: What They Are, Who Has Access to Them, and Why They Matter. Association of American Colleges and Universities, Washington, DC.

Leimer, C., Yue, H., \& Rogulkin, D. (2009). Does Service Learning Help Students Succeed? Assessing the Effects of Service-Learning at California State University-Fresno.

Lundy, B. L. (2007). Service learning in life-span developmental psychology: Higher exam scores and increased empathy. Teaching of Psychology, 34(1), 23-27.

McCubbin, I. (2003). An examination of criticisms made of Tinto's 1975 student integration model of attrition.

McKay, V. C., \& Estrella, J. (2008). First-generation student success: The role 
of faculty interaction in service learning courses. Communication Education, 57(3), 356-372.

National Student in Service Engagement. Retrieved March, 1, 2017:

http://nsse.indiana.edu/html/about.cfm

Novak, J. M., Markey, V., \& Allen, M. (2007). Evaluating cognitive outcomes of service learning in higher education: A meta-analysis. Communication Research Reports, 24(2), 149-157.

Pascarella, E. T., \& Terenzini, P. T. (2005). How college affects students (Vol. 2). K. A.Feldman (Ed.). San Francisco, CA: Jossey-Bass.

San Francisco State University Fall 2017 Student Population Infographic. (2018, May). Retreived from https://air.sfsu.edu/ir/highlights

Shields, C. M. (2010). Transformative Leadership: Working for Equity in Diverse Contexts. Educational Administration Quarterly, 46(4), 558-589.

Strage, A. A. (2000). Service-learning: Enhancing student learning outcomes in a college-level lecture course. Michigan Journal of Community Service Learning, 7,5 .

Student Success and Graduation Initiative. (2017, May). Retrieved from $\underline{\text { http://studentsuccess.sfsu.edu/content/graduation-initiative-2025-goals }}$

Terenzini, P.T., Springer, L., Yaeger, P. M., Pascarella, E.T., \& Nora, A. (1996). Firstgeneration college students: Characteristics, experiences, and cognitive development. Research in Higher Education, 37, 1-22. 
Tinto, V. (1975). Dropout from higher education: A theoretical synthesis of recent research. Review of Educational Research, 45(1), 89-125.

Tinto, V. (1982). Limits of theory and practice in student attrition. The Journal of Higher Education, 687-700.

Warren, J. L. (2012). Does Service-Learning Increase Student Learning?: A Meta-Analysis. Michigan Journal of Community Service Learning, 18(2), 56-61.

Watson, C. E., Kuh, G. D., Rhodes, T., Light, T. P., \& Chen, H. L. (2016). ePortfoliosThe eleventh high impact practice. International Journal, 6(2), 65-69.

U.S. Department of Education. (2014). Digest of Education Statistics. National Center for Education Statistics. Retrieved from https://nces.ed.gov/programs/digest/2016 menu tables.asp 
Appendix A

Intro Questions

Qualitative Interview for Service-Learning (SL) Students

- Can you explain to me how you decided to attend this university?

- What SL classes have you taken? (Multiple: Most positive? Least?)

- Why did you choose to register in a SL course as suppose to a non-SL course?

Service-Learning Class

- What were you expecting the SL class was going to be like?

- Did you have any concerns about taking a SL class?

- What were you looking forward to about the SL class?

- How did this SL class compare to other courses you have taken that are not SL?

Difference in Learning

- Do you think participating in SL helped you learn? (Example?)

- Do you think you learned differently when taking the SL class compared to your other courses? (Example?)

Reflections

- What types of reflections did you do in class to help make connections between service \& learning? (Example?)

- Did your professor give any assignments that helped you reflect on your experiences between what you were learning in class and the real world? (Example?)

- Describe any academic connections you see between the course material in the SL class and the work you did in the community. (Example?)

Quality of Interactions

- Do you think that your experiences in SL helped you interact or think differently with 1) peers, 2) faculty, and 3) community? (Examples?)

Retention and Graduation

- Do you think these SL experiences helped you to continue to stay in college? (Why? Why Not?)

- Do you think these SL experiences are helping you graduate from college? (Why? Why Not?)

- Do you think these SL experiences helped you prepared to succeed in the workforce? (Why? Why Not?)

- Do you think that participating in a SL class influenced goals you have for yourself in the short term or long term? (Examples?)

Final Thoughts

- Do you think that participating in SL has helped you be a better student?

- On a scale from 1 to 5 , how valuable did you find the service-learning course?

- As a first-generation student, would you recommend someone who is just like you to take a SL class? Why?

- Any final comments about your service-learning experience? 
Appendix B

Intro Questions

Interview Questions for None Service-Learning Students

- Can you explain to me how you decided to attend this university?

- Have you ever taken a service-learning class?

- Any particular reason why you haven't registered for a service-learning course?

- What do you think a service-learning class would be like?

- Do you have any concerns about taking a service-learning class?

Difference in Learning

- Think about a class you've taken in the past, that was really good; What was it that made it such a good class?

- Do you think participating in these good classes help you learn? (Example?)

- Do you think any of your good classes helped you learn differently?

Reflections

- What types of reflections did you do in the good classes that helped you make connections between the school and the real world? (Example?)

- Did these good classes give any assignments that helped you reflect on your experiences between what you were learning in class and the real world?

- Describe any academic connections you see between the course material in these good classes and the work you do in the real world.

Quality of Interactions

- Do you think that these good classes helped you interact or think differently with 1) peers, 2) faculty, and 3) community? (Examples?)

Retention and Graduation

- Do you think these good classes helped you to continue to stay in college? (Why? Why Not?)

- Do you think these good classes are helping you graduate from college? (Why? Why Not?)

- Do you think these good classes helped you prepared to succeed in the workforce? (Why? Why Not?)

- Do you think that participating in these good classes influenced goals you have for yourself in the short term or long term? (Examples?)

Final Thoughts

- Do you think that participating in these good classes has helped you be a better student? (Examples?)

- On a scale from 1 to 5, how valuable did you find these good course? (Why?)

- As a first-generation student, would you recommend someone who is just like you to take a SL class? Why?

- Any final comments about your experience in these good classes? 
Appendix C

Data Analysis Plan

Recoding and Arranging Variables

1. Merge 2014 and 2017 SFSU NSSE Data

2. Merge 2014 and 2017 SFSU Academic Institutional Research (AIR)

3. Merge SFSU NSSE and AIR data

4. Recode Service-Learning variable

a. Nominal Service-Learning Variable: Yes and No

b. Create Dummy Variables: FGCS\&SL, NFGCS\&SL, FGCS\&NSL, \& NFGCS\&NSL

Descriptive Statistics

Freshmen and Seniors

1. Frequencies and percentage of Sex

2. Frequencies and percentage of Race

3. Frequencies and percentage of First-Generation Status

4. Frequencies and percentage of Service-Learning

5. Mean, SD, frequencies, and percentage of Fall GPA

6. Mean, SD, frequencies, and percentage of Spring GPA

Freshmen Only

1. Frequencies and percentage of Continuation

2. Mean, SD, frequencies, and percentage High School GPA Seniors Only

1. Frequencies and percentage of Transfer

2. Frequencies and percentage of Type of Degree

3. Frequencies and percentage of Second Degree

4. Mean, SD, frequencies, and percentage Years to Degree

Bivariate Analysis Plan: Service-Learning $=$ Yes or No (Nominal)

Freshmen

- Cumulative GPA (Ratio) vs. Service-Learning (Nominal)= ANOVA

- Retention (Nominal) vs. Service-Learning (Nominal) $=$ Chi-Square Seniors

- Cumulative GPA (Ratio) vs. Service-Learning (Nominal) = ANOVA

- Graduation (Nominal) vs. Service-Learning (Nominal) $=$ Chi-Square

- Years to Degree $($ Ordinal) vs. Service-Learning $($ Nominal $)=$ Chi-Square 
Appendix D

Recruitment Flyer

\section{Partieipants Needed!}

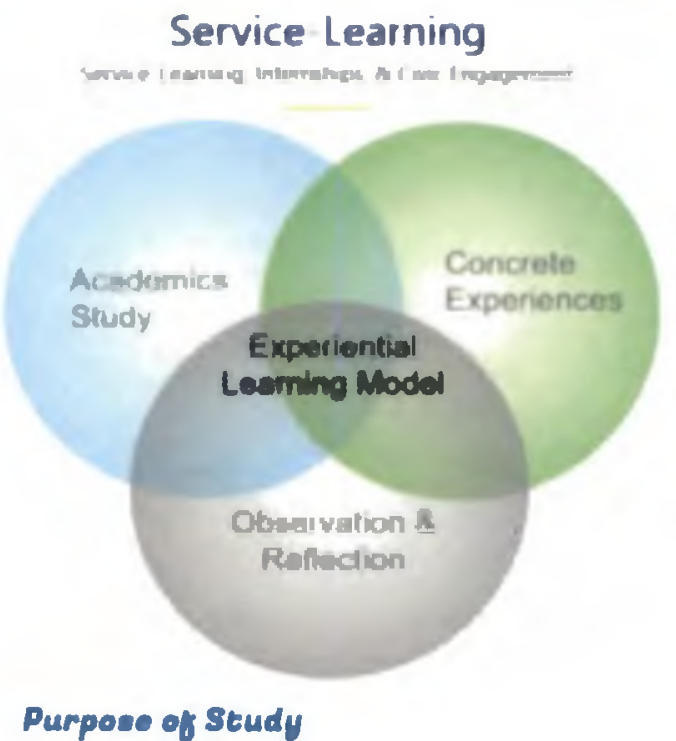

The study looks of the effects of service-learning on the academic success of first-generation college students at SF State University.

\section{How to Partiolpato}

Interviews will take 30-45 minutes. They will take place at the SF State library. Times and dates to interviews are flexible.

\section{Benefite ce Partiolpation}

II you answered YES to the questions above you are eligible to take part in the SF State study.
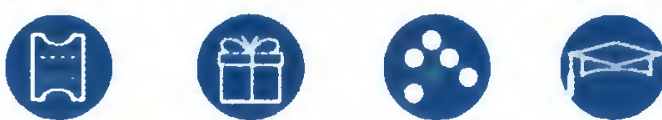

Enter
Infme

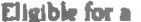
Digible for

Share your Experiance
Are you a

First-Cenoration

College Student?

Are you taking (or have taken) a servieo-loarning course?

\section{Are you an SFSU student?}

Is you are interested or have any questons, oonteret:

\section{Contaot:}

Jose R. Lopez -

Doctoral Student, SF State

Educational

Leadership

Ed.D. Program

\section{Emall:}

jirlopezlasfsu.edu

Phone:

\section{8-644-3746}

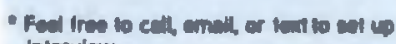
Iniverviow. 